University of Massachusetts Amherst

ScholarWorks@UMass Amherst

Masters Theses

Dissertations and Theses

July 2021

\title{
Parental Conflict in the Context of Multiethnoracial Relationships
}

Christina A. Rowley

University of Massachusetts Amherst

Follow this and additional works at: https://scholarworks.umass.edu/masters_theses_2

Part of the Clinical Psychology Commons

\section{Recommended Citation}

Rowley, Christina A., "Parental Conflict in the Context of Multiethnoracial Relationships" (2021). Masters Theses. 1071.

https://doi.org/10.7275/21715396.0 https://scholarworks.umass.edu/masters_theses_2/1071

This Open Access Thesis is brought to you for free and open access by the Dissertations and Theses at ScholarWorks@UMass Amherst. It has been accepted for inclusion in Masters Theses by an authorized administrator of ScholarWorks@UMass Amherst. For more information, please contact scholarworks@library.umass.edu. 
Parental Conflict in the Context of Multiethnoracial Relationships

A Thesis Presented

by

CHRISTINA A. ROWLEY

Submitted to the Graduate School of the University of Massachusetts Amherst in partial fulfillment of the requirements for the degree of

MASTERS OF SCIENCE

May 2021

Clinical Psychology 
(C) Copyright by Christina A. Rowley 2021 All Rights Reserved 
Parental Conflict in the Context of Multiethnoracial Relationships

A Thesis Presented

by

CHRISTINA A. ROWLEY

Approved as to style and content by:

Maureen Perry-Jenkins, Chair

Elizabeth Harvey, Member

Evelyn Mercado, Member

Caren Rotello, Department Head

Psychological and Brain Sciences 


\section{DEDICATION}

This thesis is dedicated to my mother, Guadalupe Ortiz. Without you and your journey, there would be no me - a biethnoracial researcher. You inspired me to learn and relentlessly pursue whatever I set my mind to. 


\section{ACKNOWLEDGEMENTS}

I am grateful to many people but would like to start by sincerely thanking my advisor, Dr. Maureen Perry-Jenkins, who supported me through this entire thesis writing process. She encouraged me to read, write, and revise which helped me develop and grow as a researcher. She was open to my inquiries and encouraged me to pursue my research interests. I could not thank her enough for her role in completing this thesis and for reaching this stage of my doctoral process.

Last, I could not finish without thanking my family, without which this journey would not be possible. Thank you for always believing in me and for hanging in there with me. 


\begin{abstract}
PARENTAL CONFLICT IN THE CONTEXT OF MULTIETHNORACIAL RELATIONSHIPS
\end{abstract}

MAY 2021

CHRISTINA A. ROWLEY, B.A., UNIVERSITY OF CALIFORNIA IRVINE M.S., CALIFORNIA STATE UNIVERSITY FULLERTON M.S., UNIVERSITY OF MASSACHUSETTS AMHERST

Directed by: Professor Maureen Perry-Jenkins

The percent of families with parents from different racial or ethnic backgrounds has risen exponentially in the last decades. Approximately $14 \%$ of children were born into multiethnoracial (MER) families in the United States in 2015, more than double the rate from 1980 (Bialik, 2017). Studies show that MER couples are more likely to separate or divorce than their monoethnoracial (MoER) counterparts, perhaps due to greater conflict stemming from differing values, coping strategies, and conflict management styles and decreased access to family and community support (Fu, Tora, \& Kendall, 2001; Zhang \& Van Hook, 2009). With the growing rates of MER couples, there has been increased interest and research addressing the unique benefits and challenges of being in a MER relationship. It is likely that the challenges that arise in MER families peak across the transition to parenthood when couples must negotiate how to merge their respective values, behaviors, and beliefs into a new family unit. The proposed study examines how the ethnoracial composition of couples (i.e., same versus different racial/ethnic backgrounds) predicts levels and increases in coparental conflict across early parenthood; and, in addition, the role of familial support as both a mediator and 
moderator of this relationship. Identifying the processes linking couples' ethnoracial composition to the quality of family relationships could help inform parent interventions to better support MER parents across the transition to parenthood. 
ABSTRACT vi

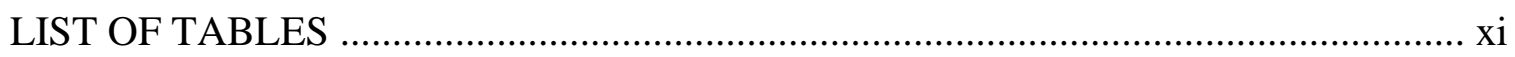

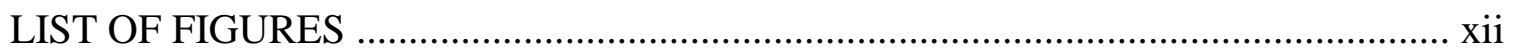

\section{CHAPTER}

I. PARENTAL CONFLICT AND MULTIETHNORACIAL RELATIONSHIPS .... 1

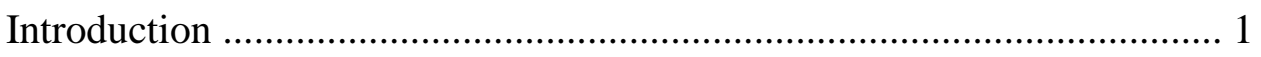

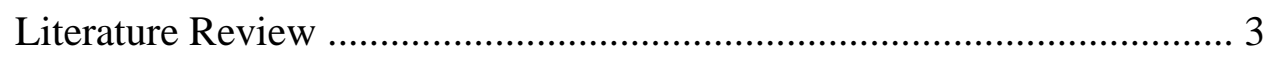

Defining Multiethnoracial Relationships .............................................. 3

Challenges in Multiethnoracial Relationships ....................................... 5

Conflict in Multiethnoracial Relationships .............................. 12

Coparenting in Multiethnoracial Relationships ........................ 14

Social Support in Multiethnoracial Relationships .................... 18

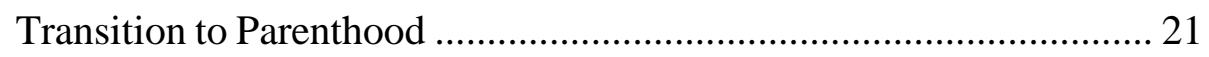

Multiethnoracial Dyads and the Transition to Parenthood ...... 22

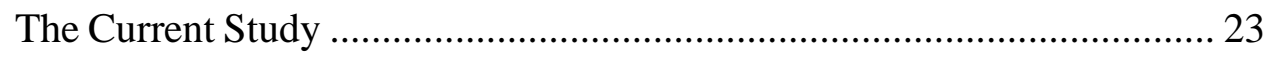

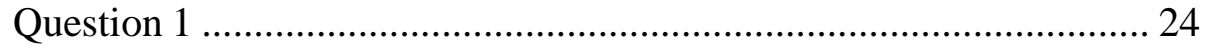

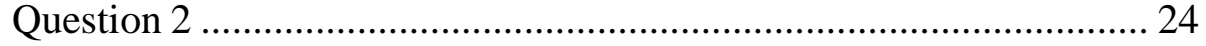

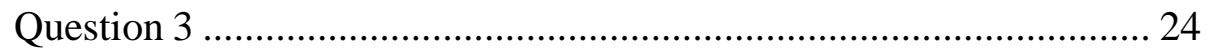

Question 4 ........................................................................... 25

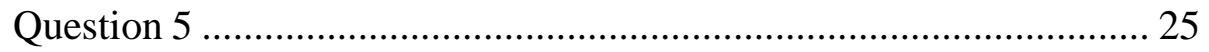

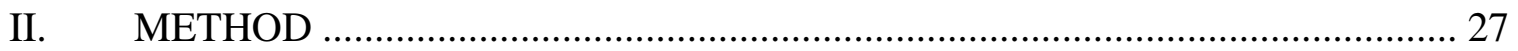

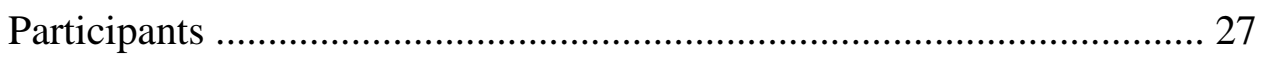

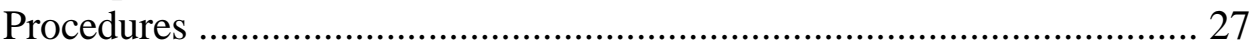

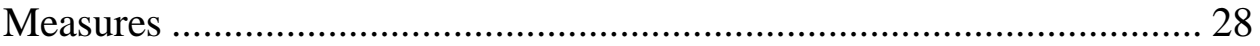

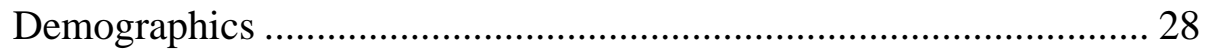


Co-parental Conflict ............................................................. 29

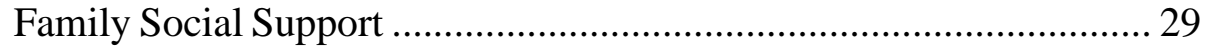

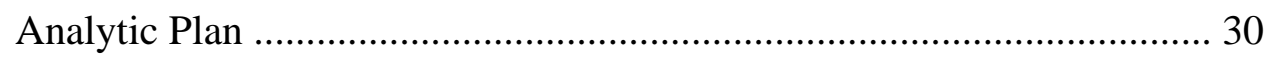

Partner Effects .................................................................... 35

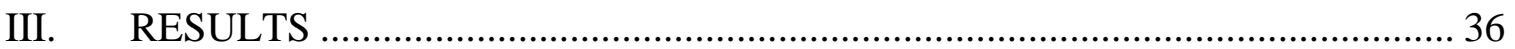

Descriptive Statistics ..................................................................... 36

Co-parental Conflict in Multiethnoracial and Monoethnoracial Parent Dyads ....

Total Effects Models: Levels ............................................................... 42

Total Effects Models: Change ............................................................ 42

Moderation Models ................................................................................ 44

Mediation Models ............................................................................ 48

Exploratory Analyses .................................................................. 51

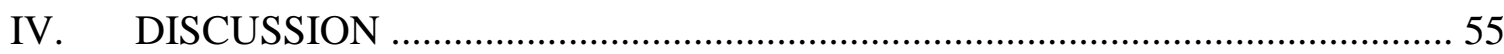

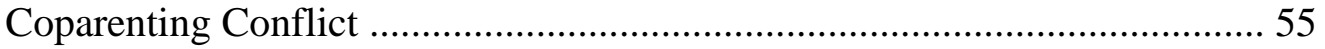

Coparenting Conflict and Family Support ....................................... 58

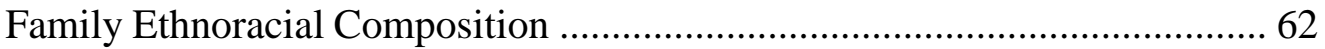

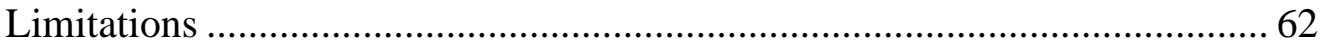

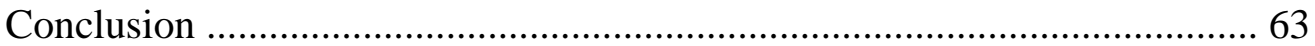

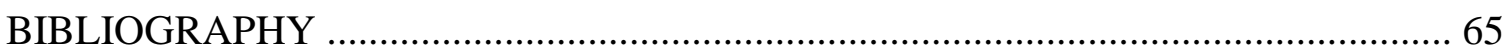




\section{LIST OF TABLES}

Table

1. Breakdown of Multiethnoracial and Monoethnoracial Couples ............................... 36

2. Participant Demographics by Ethnoracial Category ............................................ 37

3. Descriptive Statistics for Mothers' and Fathers' Family Support and Coparenting

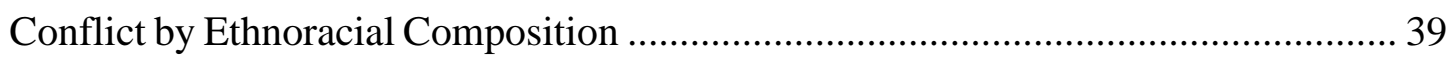

4. Relationships Between Covariates and Outcome Variables .................................... 41

5. Unstandardized Associations Between Ethnoracial Composition on Mothers and

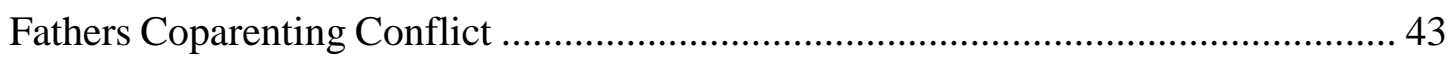

6. Unstandardized Interaction Between Ethnoracial Composition and Family Support at $\mathrm{T} 1$ 46

7. Unstandardized Interaction Between Ethnoracial Composition and Family Support at $\mathrm{T} 4$

8. Unstandardized Associations Among Ethnoracial Composition, Family Support, and Coparenting Conflict 51

9. Descriptive Statistics for Family Support and Coparenting Conflict with Expanded Ethnoracial Composition Categories 54

10. Descriptive Statistics for Family Support and Coparenting Conflict with Expanded Ethnoracial Composition Categories by Gender 55 


\section{LIST OF FIGURES}

Figure

Page

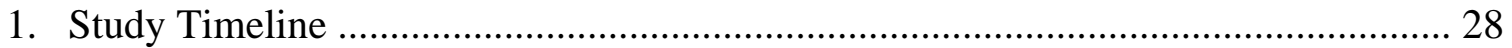

2. Mothers' Coparental Conflict Across Early Parenthood ........................................ 43

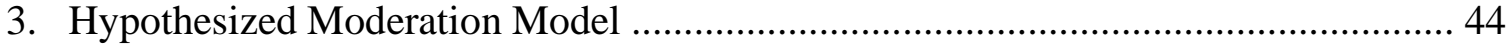

4. Interaction Effect of ERC x Family Support on Fathers' Coparenting Conflict ......... 48

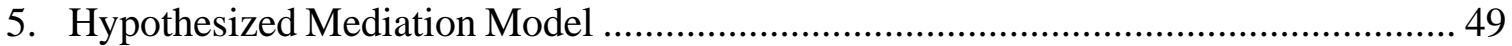




\section{CHAPTER I}

\section{PARENTAL CONFLICT AND MULTIETHNORACIAL RELATIONSHIPS}

Approximately ten percent of marriages in the United States in 2015 were between people of different races or ethnicities, which is more than double the rate of 1980 (Bialik, 2017). Consequently, the percentage of multiracial children in the United States has increased from roughly one percent in 1970 to 14 percent in 2015 (Bialik, 2017). These rates are projected to increase exponentially in decades to come. With the growing number of multiethnoracial (MER) couples, there has been some attention given to the benefits of these relationships, such as enhanced consciousness of racial or ethnic issues and the ability to identify commonalities between different cultural backgrounds (Crippen \& Brew, 2013; Sengstock, 2001). Research also points to challenges of being in MER relationships (e.g., Kawano, 2015; Kroeger \& Williams, 2011; Sengstock, 2001; Tophoven, 2014). For example, studies have shown that partners within couples that are of different racial or ethnic backgrounds are less happy in their relationships and have higher rates of dissolution than couples with partners from the same racial or ethnic background (Fu et al., 2001; Zhang \& Van Hook, 2009). These more negative outcomes may be due to greater conflict stemming from differing values, coping strategies, and conflict management styles (Bustamante, Nelson, Henriksen, \& Monakes, 2011).

Research indicates that for most adults the transition to parenthood is a challenging family event (Huston \& Holmes, 2004), marked by a general decrease in marital satisfaction and positive couple communication (Doss, Rhoades, Stanley, \& Markman, 2009) and increases in conflict. It is likely that parenting challenges may peak at this time for MER families as parents must incorporate the values, behaviors, and 
beliefs of two unique cultures into a new family system. Not only is this transition an important period of adjustment for new parents, but the perinatal period (extending from pregnancy to one-year postpartum) is also an important period of development for the child. The developing fetus and newborn are especially vulnerable to environmental effects, including maternal stress during pregnancy and through the first year of life (Belsky \& Pluess, 2009). Early risk factors, experienced both prenatally and postnatally, such as high parental conflict, have been linked to poorer birth outcomes (e.g., premature birth, low birth weight) and poorer developmental outcomes in children (Buitelaar, Huizink, Mulder, de Medina, \& Visser, 2003; Graignic-Philippe, Dayan, Chokron, Jacquet, \& Tordjman, 2014). Therefore, it is important to understand how the challenges facing MER couples, such as differences in cultural values, communication patterns, and conflict styles, may increase their risk for conflict and dissolution.

In addition to the increased risk for parental conflict in MER couples, researchers have found that MER couples experience decreased social support as compared to monoethnoracial (MoER) couples (Bratter \& Whitehead, 2018). Social support is a protective factor for parents during the transition to parenthood (Bost, Cox, Burchinal, \& Payne, 2002) and is associated with improved quality of parenting behavior (Burchinal, Follmer, \& Bryant, 1996), improved parent-child relationship quality (Armstrong, BirnieLefcovitch, \& Ungar, 2005), and decreases in parental depressive symptoms (Bost et al., 2002). MER dyads may perceive less social support from family (due to disapproval of MER relationships) leading to higher levels of coparenting conflict (Bratter \& Whitehead, 2018). On the other hand, high levels of social support may buffer (moderate) the effects of ethnoracial couple match on coparenting conflict. For MER dyads, 
coparenting conflict social support may be especially protective since they are at greater risk for experiencing isolation from their family, friends, and the community (Ngai \& Ngu, 2014). The proposed study examines how the ethnoracial composition of couples (i.e., same versus different racial/ethnic backgrounds) predicts levels and increases in coparental conflict across the transition to parenthood. In addition, the role of familial support is examined as a possible mediator, linking couples' ethnoracial composition to coparental conflict, and as a possible buffer, or moderator, of the negative connection between ethnoracial match and conflict.

\section{Literature Review}

\section{Defining Multiethnoracial Relationships}

A variety of different terms have been used to describe couples in which partners are from two different racial or ethnic backgrounds such as: intermarriage (Yahirun, 2019), cross-cultural (e.g., Falicov, 1995), cross-national (e.g., Seto \& Cavallaro, 2007), biracial (e.g., Roy \& Rollins, 2019), interracial (e.g., Usita \& Poulsen, 2003), mixed-race relationships (e.g., Bratter \& Whitehead, 2018), and multiracial couples (e.g., Wilt, 2011). The term "intermarriage" is broad in scope and refers to individuals from two different racial or ethnic backgrounds, in addition to different religious, socioeconomic, or national backgrounds (Yahirun, 2019). Since the current study will focus on couples from the United States coming from two different racial or ethnic backgrounds, the term "intermarriage" is too broad. Similarly, the terms "cross-cultural" and "cross-national" usually refer to couples from two different racial or ethnic backgrounds but might include people from different countries. As such, these terms are not appropriate for the current research as couples that come from different countries have their own unique sources of 
stress (Seto \& Cavallaro, 2007) not relevant to the current sample. In contrast, the term “interracial”, which has, historically, been used to describe relationships between people from different racial backgrounds, is connected to an oppressive and violent period in U.S. history, (i.e., the civil rights movement of the 1960s, when interracial marriages first became legal) (Legal Information Institute, 2016). Besides being a term that only refers to race, interracial also conjures up political ideologies and a historical legacy of racism.

Finally, the term "multiracial” has been used by many scholars (Dalmage, 2000; Rosenblatt, Karis, \& Powell, 1995; Thomas, Wetchler, \& Karis, 2014; Tubbs \& Rosenblatt, 2003; Wilt, 2011) to represent both racial and ethnic identity since people with various ethnic identities (i.e., Latinx) often identify with their ethnicity and not a race. Race and ethnicity are both socially constructed categories that are historically linked to the color of a person's skin (Burton, Bonilla-Silva, Ray, Buckelew, \& Freeman, 2010; Shih, Bonam, Sanchez, \& Peck, 2007; Smedley \& Smedley, 2005). In fact, when racial and ethnic categories were first constructed, they included the terms white, black, yellow, red, and brown to be associated with people from European, African, Asian, Indigenous, and Latinx backgrounds. Racial and ethnic categories in the United States originated as a method of separating people by color and race; they are malleable categories "rooted in both macro and micro social processes, and... [have] structurally and culturally defined parameters" (Rockquemore \& Brunsma, 2002). Given the broad and changing meanings of both race and ethnicity in American society, the term "multiracial" does not fully capture the term ethnicity. Thus, the term "multiethnoracial" (MER) will be used in the current study to describe couples from different racial and ethnic backgrounds. This term is most appropriate given that race and ethnicity are the 
focal points of the paper, instead of nationality, religion, or socioeconomic status, and this term allows us to consider couples in which one or both partners may be multiracial individuals themselves.

\section{Challenges in Multiethnoracial Relationships}

Most couples when entering a relationship experience adjustments and conflict as they merge their separate backgrounds. These adjustments might involve negotiations about the degree to which they will maintain or integrate friend networks, balance time with their own and their partner's extended family (Kearns \& Leonard, 2004), and negotiate the division of household tasks (Kluwer, Heesink, \& Vliert, 2000). Multiethnoracial (MER) couples, while dealing with these typical adjustments, often have an added level of complexity related to merging different cultural backgrounds and values. In this context, culture is broadly defined as the shared values, traditions, and ways of relating to people that are learned within social groups (e.g., race/ethnicity, nationality, sexual orientation) and passed down from generation to generation (American Psychological Association, 2017; Bohannan, 2010). In this study, culture will refer to the norms, values, traditions, and ways of relating to others that are typically shared within different racial or ethnic groups.

Although there is variability within cultures related to family values and traditions, cross-cultural studies have consistently found that people from similar nationalities or racial/ethnic backgrounds cluster together along cultural values (Minkov \& Hofstede, 2012b). Individuals within the same cultures or countries of origin typically share common values, language, and traditions (Taras, Rowney, \& Steel, 2009). Hofstede was the first to conduct a large-scale, cross-national study that examined whether people 
from different countries shared core values (McSweeney, 2002). Using data from a multinational information technology company representing participants from 64 countries, Hofstede, (1980, 1983, 1986) examined different values across nationalities and cultures. He found that people tend to differ along five dimensions. The first dimension, individualism versus collectivism, refers to the tendency for individuals to focus primarily on their own interests or those of their immediate family (defined as husband, wife, and children), versus those from more collectivistic backgrounds where the good of the broader family (defined as parents, siblings, grandparents, aunts, uncles, and so on) is prioritized (Hofstede, 1986). People from collectivistic backgrounds are expected to maintain unconditional loyalty to their family and protect the interest of its members (Guzley, Araki, \& Chalmers, 1998). Couples that differ substantially on the degree to which they are individualistic or collectivistic may have a harder time understanding one another's viewpoints. For example, an individual with more individualistic values may have trouble understanding the importance of maintaining connections to extended kin (Xiang, Hoot, \& Raisor, 2017) or caring for kin (e.g., mothers or grandmothers) (Kamenou, 2008). A person with more collectivistic values, in contrast, may have trouble understanding an individualistic person's motivation to pursue academic or job interests that do not align with the interest of the extended family. In each of these cases, the misalignment in family values can cause (or lead to) increased chances for conflict.

Second, all cultures have degrees of inequality within them, but different cultures vary in the extent to which inequalities in power are tolerated by members of that society, primarily those with less power. This dimension is referred to as the power distance 
dimension (Hofstede, 1986). This value may play out in distinct ways for MER couples. For example, parents might disagree about power differentials in the parent-child relationship. Someone with an authoritarian parenting style might expect there to be a greater power differential between parents and children compared to someone with an authoritative style. In the United States, parents from a minority racial or ethnic background (e.g., Black, Latinx, Asian) are more likely to parent with an authoritarian style; whereas, White parents are more likely to parent with an authoritative style (Halgunseth, Ispa, \& Rudy, 2006; Pinderhughes, Dodge, Bates, Peltit, \& Zelli, 2000). Another way individuals might differ on this dimension is through parental expectations regarding respect for elders or other people in authority positions. For example, East Asian, Vietnamese, Indian, and Latinx families teach their children to be obedient towards elders within their family and that their actions have consequences not only for themselves but for the entire family (Harwood, Leyendecker, Carlson, Asencio, \& Miller, 2002). This is distinct from values of independence and autonomy typically taught to White American children (Johnson, Radesky, \& Zuckerman, 2013). Thus, conflict might stem from the degree to which parents or dyads disagree on the power distance within relationships with inherent power differentials (e.g., parent/child, employee/employer).

Third, people from different cultural backgrounds tend to differ in their uncertainty-avoidance which refers to the degree of anxiety people feel about situations perceived as "unstructured, unclear, or unpredictable" and the efforts they make to avoid them (Hofsteade, 1986). Unstructured situations are defined as being different than what is expected or what is usual. People who are highly avoidant tend to create strict rules and inflexibly believe in absolute truths. Since uncertainty is threatening, institutions and 
regulations that create certainty are more valued. Couples who differ in their uncertainty avoidance might need to have extended negotiations about the expectations regarding their children's behavior and discipline when transitioning to parenthood. For instance, one parent might be more inclined to "go with the flow" while the other might experience greater anxiety about the unknowns and uncertainty of parenthood. The more avoidant parent may create more rigid rules for the family, leading to greater anxiety for this member of the couple when those rules are violated. Thus, as the inevitable conflicts of parenting arise, and uncertain situations come up or rigid rules are violated, members of MER dyads may process these events differently.

Fourth, masculinity versus femininity refers to how much a culture strives for distinction between men and women. The characteristics that distinguish men and women in more masculinized cultures are stereotypic (e.g., men would be aggressive, competitive, ambitious while women would be caring, accommodating, emotional). According to Hofstede (1986), masculine cultures are more likely to value material success, while feminine cultures are more likely to value interpersonal relationships and concern for the oppressed or powerless. Different cultures fall on a continuum of this dimension, with some cultures falling on the extremes either being highly masculinized or egalitarian, and others falling somewhere in the middle. Couples from cultures who differ on this dimension might begin new relationships with different expectations about gender equity (Bianchi, Sayer, Milkie, \& Robinson, 2012; Davis \& Greenstein, 2009; Kellner, 2009; Lachance-Grzela \& Bouchard, 2010; Yavorsky, Kamp Dush, \& SchoppeSullivan, 2015), increasing the likelihood for dissatisfaction in unmet expectations. Unmet gender equity expectations are related to dissatisfaction and decreased marital 
quality in all couples, regardless of race or ethnicity (Davis \& Greenstein, 2009; Jackson, Miller, Oka, \& Henry, 2014; Mickelson, Claffey, \& Williams, 2006). The degree to which expectations are violated might be exacerbated in dyads that come from different cultural backgrounds. For example, White women partnered with Black men in MER relationships tend to do less housework compared to White women partnered with White men (Bolzendahl \& Gubernskaya, 2016). In contrast in this same study, when partnered with Latinx men, White women tended to do more housework than if partnered with White or Black men. This may be due to value differences between ethnic groups regarding gender roles related to the division of household chores and childcare tasks (McLoyd, Cauce, Takeuchi, \& Wilson, 2000). Thus, conflict might arise if it is expected that one parent perform more household or childcare tasks based on what is customary for their gender within their cultural background, and expectations become violated due to misalignment of their values (Forry, Leslie, \& Letiecq, 2007). This is just one example of how differences on the masculinity/femininity dimension might create conflict that spills over to child-rearing.

Minkov and Hofstede (2012a) identified the fifth and final dimension as time orientation (short versus long term orientation). Time orientation refers to the value people from different cultural backgrounds place on time. Western cultures tend to have a short-term orientation and be monochronic which means that time is thought of as linear, people are expected to do one task at a time, and lateness is not tolerated (Lindquist \& Kaufman-Scarborough, 2007). In contrast, eastern cultures tend to have a long-term orientation and be polychronic which means they tend to think of time as cyclical, engage less in formalized tasks, are less focused on precise scheduling, and are guided by 
tradition and relationships (Lindquist \& Kaufman-Scarborough, 2007). Individuals within a couple who come from these two distinct orientations may have greater conflicts around arriving "on-time" to doctor visits, parties, or school functions; the pace of their movements in public places (e.g., grocery stores, shopping malls); or getting out of the house for an event.

Building on Hofstede's research on the five value dimensions that appear across cultures, Kirkman and colleagues (2006) conducted a review of studies that examined these five cultural dimensions over the past two decades. Results overwhelmingly confirmed the existence of these cultural dimensions. Moreover, researchers have demonstrated that people who emigrate from different countries tend to retain their ancestral cultural customs and values (e.g., Berry, 1997; Chun \& Akutsu, 2003; Sam, Vedder, Leibkind, Neto, \& Virta, 2008). One method by which this happens is that people tend to live in areas with a greater concentration of people from the same racial or ethnic background; whether it be because of structural or systemic inequalities (Kaplan \& Woodhouse, 2004; Boustan, 2013) or because they are drawn to people with similar customs and values from their home country (Bobo \& Zubrinsky, 1996). Thus, even within the United States, these cultural dimensions are useful in theorizing how differences on these five cultural dimensions might lead to greater sources of conflict as couples' expectations are violated and differences are negotiated as they cope with new parenthood.

Importantly, some of the differences in cultural beliefs discussed above (i.e., independence versus interdependence, obligation toward family) have also been shown to differ by social class (Kraus, Piff, \& Keltner, 2011; Lareau, 2011). Kraus and colleagues 
(2011) go as far as to describe social class as another cultural identity. One example is that parents in middle- and upper-class families actively foster their children's individual talents and skills and maintain continuous efforts to stimulate their children's development through activities outside the home. Whereas parents in working-class and poor families view children's development as more spontaneous and structure their children's time in and around the home usually engaging in free play with peers and family members (i.e., cousins, siblings) (Lareau, 2011).

Another class-based difference in families is the power-distance dynamic between parents and children. In middle- and upper-class families, boundaries are less clear between parents and children, and children are allowed to negotiate and reason with their parents. In working-class and poor families, the boundaries are marked clearly and rigidly leading to less speech between parents and children (including whining and badgering from children) (Lareau, 2011). Examining the experience of MER families in workingclass samples, as is done in this study, essentially controls for social class effects, isolating the effects of race or ethnicity, and the match between partners, family support and conflict (Howell, Mora, \& Levanthal, 2006).

The transition to parenthood is a time when cultural differences may become magnified. Expectant and new parents must negotiate a number of issues and decisions during the transition to parenthood, such as the naming of their children, beliefs about spoiling, sleeping and eating, the expectations they will have of their children (such as their sense of obligation to the family), and the method by which the children should express themselves. When parents are from the same ethnic or racial background, it is likely that they share more similar values and expectations than MER couples around 
these issues. Parents from different racial or ethnic backgrounds may struggle as their expectations are violated and differences require greater negotiation and compromise than their monoethnoracial (MoER) counterparts.

\section{Conflict in Multiethnoracial Relationships}

Researchers theorize that the dissimilarities in cultural values within a couple's relationship, such as the values described by Hofstede's cultural dimensions, are likely to result in greater conflict and distress for multiethnoracial (MER) couples (Crippen \& Brew, 2007). In addition to differing dimensions of culture, individuals from different racial or ethnic groups often differ in their concepts of self (DeCicco \& Stroink, 2007; Markus \& Kitayama, 2010), communication styles (Gudykunst, Ting-Toomey, \& Chua, 1988), conflict styles (Hammer, 2005), and experiences of discrimination and privilege (Kendall, 2012; Schmitt \& Branscombe, 2002). All these characteristics inform the way individuals within a dyad perceive and react to their experiences and influence how they interact within the dyad (Crippen \& Brew, 2007). Thus, people coming together from similar racial or ethnic backgrounds (i.e., MoER couples) will more likely be similar along these aspects of culture which will not be a source of conflict like it might be for MER couples.

Although several researchers theorize that these dissimilarities will result in greater conflict for individuals in MER relationships (Bratter \& King, 2008; Crippen \& Brew, 2013; Kang Fu \& Wolfinger, 2011; Sharaievska, Kim, \& Stodolska, 2013), no study, to our knowledge, has investigated whether relationship conflict is higher in MER couples compared to MoER couples. Studies that have looked at dissolution in MER relationships theorize that couples separate due to increased relationship conflict; yet few 
have directly investigated parental conflict. More often researchers focus on outcomes like personal distress and mental health. There is evidence that being in a MER relationship is related to greater levels of personal distress (Bratter \& Eschbach, 2006; Kroeger \& Williams, 2011), although this seems to vary by ethnoracial composition. Specifically, Bratter and Eschbach (2006) found that White women in relationships with Black men, Native-American men in relationships with women from any other background, and Latinx individuals in a relationship with individuals from any other background experience the greatest levels of distress and depression compared to individuals in other ethnoracial dyads. Additionally, Kroeger and Williams (2011) found that non-Black individuals with Black partners experience the greatest depression and lowest marital satisfaction. Thus, there is some evidence that being in a MER relationship presents more challenges, although the reasons are not yet clear. Moreover, these findings suggest that conflict or strain within close relationships may be more evident in certain ethnoracial compositions than others.

There are gaps in our knowledge regarding how different ethnoracial compositions are related to personal and relational outcomes in MER families and the results, to date, are not consistent. One challenge is that many studies are simply not powered to examine differences among different types of ethnoracial dyads. In addition, some studies have greater rates of MER relationships involving Latinx partners usually in Western parts of the United States (Crippen \& Brew, 2013), while others have greater rates of MER relationships involving Black-White dyads usually in the Southern parts of the United States (Kroeger \& Williams, 2011). Still other studies include classifications based more on nationality instead of race. Larger sample sizes also allow researchers to 
investigate more diverse groups of MER dyads, whether gender interacts with the effects of ethnoracial pairing, and whether there are partner crossover effects within MER dyads. Further investigation of how ethnoracial composition within the dyad relates to conflict is necessary to determine which dyads in MER relationships might face the greatest challenges.

\section{Coparenting in Multiethnoracial Relationships}

Coparenting refers to the ways in which parents support or undermine each other to fulfill their parental responsibilities and work together to meet their children's needs (Le, McDaniel, Leavitt, \& Feinberg, 2016; Margolin, Gordis, \& John, 2001). The coparental relationship is distinct from the romantic relationship. Specifically, the coparenting literature, which first emerged in divorce research, specifically focuses on understanding how parents continue to have a relationship after divorce and learning how the quality of the coparenting relationship impacts children's adjustment. More recently, researchers have investigated coparenting in intact families to understand how the coparenting relationship, distinct from the marital relationship, affects children's development, family relationships, and family members' mental health. Research shows that a supportive coparenting relationship predicts better child adjustment, evidenced by greater academic achievement, fewer behavior problems, more secure attachments to caregivers, and lower internalizing and externalizing difficulties (Kolak \& Volling, 2013; Majdandžić, de Vente, Feinberg, Aktar, \& Bögels, 2012; Teubert \& Pinquart, 2010). Williams (2018) found that parents who have a more positive coparenting relationship have better mental health outcomes, such as lower rates of depression. In addition, when couples become new parents, greater coparental support is related to positive couple 
communication which contributes to a stronger romantic relationship over time as well as greater satisfaction in the romantic relationship (Pinquart \& Tuebert, 2010; Le et al., 2016).

To date, few studies have explored how coparenting may differ for monoethnoracial (MoER) and multiethnoracial (MER) couples. In an important exception, Crippen and Brew (2013) investigated the ways in which parents negotiate their cultural differences. The researchers interviewed 21 individuals in intercultural couples, defined as "dyads who describe themselves as being in a significant relationship, each of whom has a self-identified cultural background (i.e., country of origin, ethnic heritage, racial identity, and religion) that is different from their partner." The participants had to have at least one child they were raising together. All dyads, but one, were MER in which one member was of European descent and the other member was of another background (e.g., Haitian, Latino, Japanese). Results revealed a wide range of perceptions regarding cultural differences about parenting practices. Some couples reported minimal cultural differences sometimes finding commonalities within their distinct cultural values and traditions, while others highlighted differences in beliefs surrounding discipline, education, food, and expected roles of parents and children.

Based on their findings, Crippen and Brew (2013) identified five distinct ways that parents adapted to cultural differences: assimilation, cultural tourism, cultural transition, cultural amalgamation, and dual biculturalism. Assimilation is a strategy in which one parent in the dyad relinquishes their cultural heritage and conforms to the other parents' values in parenting. As such, parents that use this cultural adaptation strategy do not attempt to transmit the values from their culture of origin. Cultural 
tourism similarly involves the relinquishment of one partner's cultural values and customs. This strategy primarily involves the father relinquishing his cultural influence on decisions made around child-rearing. What distinguishes this strategy from assimilation is that there is some attempt to transmit cultural traditions through holiday celebrations, rites of passage, food, and relationships with grandparents. Cultural transition is a strategy in which cultural differences are acknowledged, and there is an attempt to transmit the cultural values and traditions of both parents equally. Parents who use this strategy usually include one parent who immigrated from other cultures or were raised in traditional immigrant households. Thus, there is tension in their ability to fully transmit both cultures since there is inherently less exposure to one parents' culture. Cultural amalgamation describes a process in which the two cultures are integrated into an intercultural blend. These parents acknowledge their cultural differences, identify elements of commonality, and work to create a third culture that uniquely blends their differences and commonalities. Last, dual biculturalism is a strategy in which parents pass down their cultural customs, traditions, and languages equally through immersion in both parents' culture and extended contact with family. It would have been interesting to know if certain types of intercultural couples were more likely to attend to their cultural differences, and which of the five cultural adaptation strategies different types of intercultural couples adhered to. Further research could address if certain strategies used to adapt to cultural differences result in greater relational or coparenting conflict for MER dyads.

Edwards, Caballero, and Puthussery (2009) explored how couples attended to culture in their families with a sample of 35 parent couples from different racial, ethnic, 
and faith backgrounds. Similar to Crippen and Brew (2013), Edwards and colleagues found that parents had a variety of ways they negotiated and compromised in the relationship regarding their cultural differences. Specifically, they identified three approaches: (a) open individualized approach (i.e., emphasizing transcendence beyond race, ethnicity, or faith), (b) mixed collective approach (i.e., integrating their cultural backgrounds), and (c) single collective approach (i.e., emphasizing the importance of one parents' culture over another to be passed down to their children).

Bhugun (2017) conducted in-depth, qualitative interviews with fourteen intercultural parents (partners from different nationalities, religion, ethnicities, and/or racial identities) living in Australia. These couples were between 28 and 67 and had between one and four children between 6 months and 18 years. Bhugun (2017) found that parents in intercultural couples describe struggling with similar parenting experiences compared to intracultural couples, such as having to negotiate disciplinary strategies for correcting behavior, whether parents agreed upon the child co-sleeping with them, and other socialization processes. However, intercultural couples differed from monoracial couples in the extent to which they argued about educational expectations, language and communication, expectations of children's role in the family, and involvement of extended family. Intercultural couples also believed that their cultural differences intensified the degree to which they disagreed about and struggled with parenting decisions.

These few studies provide accounts of multiethnoracial (MER) parents' experiences raising children and describe different ways that parents perceive and cope with their differences, but no study specifically investigates coparenting conflict. 
Moreover, these studies highlight the variability in the ways MER parents negotiate and define cultural customs, values, and traditions for their new family, suggesting that there will be variability in the way MER parents experience coparenting conflict and the topics that they disagree about in terms of parenting.

Given that the coparental relationship is an important factor in the health and adjustment of both the couple relationship and children's development, and that MER families might have more challenges related to parenting differences or expectations, it is important to investigate whether MER parents experience greater coparenting conflict compared to MoER couples. In addition, it is also important to examine specific factors that may exacerbate or buffer that conflict, namely social support. To date, no studies have examined differences in coparental conflict between MER and monoethnoracial (MoER) couples; one aim of the present investigation is to address that gap in the literature.

\section{Social Support in Multiethnoracial Relationships}

Social support can include support received or, more usually, perceived by family, partners/spouses, friends, or neighbors/communities (Chong \& Mickelson, 2016; Collins, Dunkel-Schetter, Lobel, \& Scrimshaw, 1993; Procidano \& Heller, 1983; Wellman \& Wortley, 1990). In addition, there are various types of support parents can receive including emotional (i.e., feelings of trust, care, empathy, and esteem), informational (i.e., providing information or advice), appraisal (e.g., someone to provide evaluative feedback), and/or instrumental support (i.e., providing financial support or other tangible resources such as housing or food) (House, 1981; Östberg \& Lennartsson, 2007). 
Social support has been assessed through both the quantity of social relationships (e.g., family members, friends, neighbors) as well as the quality of relationships within a person's social network (House, Landis, \& Umberson, 1988); both are important to overall well-being (Gremigni, Mariani, Marracino, Tranquilli, \& Turi, 2011) and family relationships (Armstrong et al., 2005). At least one study found that during the transition to parenthood, the effects of quality outweighed the effects of quantity in social relationships (Collins et al., 1993). Support received over the transition to parenthood from spouses and family (Bost et al., 2002), friends (Goldstein \& Genero, 1995; Richardson, Barbour, \& Bubenzer, 1995), and the community all contributed to greater parenting satisfaction and lower parenting stress (Bartholomew, Schoppe-Sullivan, Glassman, Kamp Dush, \& Sullivan, 2012). Social support for parents is positively related to children's well-being, with greater social support predicting lower externalizing and internalizing difficulties, as well as higher academic achievement (Parks, Lenz, \& Jenkins, 1992).

Social support could function in two distinct ways for multiethnoracial (MER) parents. First, social support may act as a protective factor that buffers the relationship between ethnoracial match and conflict (Ngai \& Ngu, 2014). Social support from a family member is protective during the transition to parenthood, as it buffers the effects of this transition on couple conflict (Bost et al., 2002; Wandersman, Wandersman, \& Kahn, 1980). Greater social support is associated with better relational outcmoes, such as reduced conflict and increased marital satisfaction (Ngai \& Ngu, 2014) One possible mechanism by which social support buffers the negative effects of marital conflict during 
the transition to parenthood is that greater social support increases parents' coping resources when overwhelmed by the demands of parenting (Armstrong et al., 2005).

A second way that social support might impact MER families is that being in a MER couple may reduce access to social support from extended kin (Bratter \& Whitehead, 2018). Several studies have found that individuals who enter relationships with someone from a different racial or ethnic background, are more likely to face parental disapproval, decreased social support from friends and family, and negative attitudes from the community (Bell \& Hastings, 2015; Tillman \& Miller, 2017). Negative attitudes from the community towards MER couples manifest themselves as microaggressions, violence, hate speech, and racial segregation (Glaser, Dixit, \& Green, 2002; Kim, 2013; Leslie \& Letiecq, 2004). There is some evidence that this might differ by the ethnoracial composition of the dyad, such that social support and acceptance from friends, family, and the community, might differ if the dyad includes a White partner and a partner of color or individuals from two different minority groups. Specifically, Stuberfield (2017) surveyed 82 undergraduates who were either in a bi-racial or bi-ethnic relationship and compared them to peers with partners of the same racial or ethnic groups. Interracial couples, on average, reported less support and acceptance from family and friends. However, White participants in interracial relationships viewed their community as less accepting of interracial relationships than all other racial groups. In a related study, Bratter and Whitehead (2018) found that ethnicity of the mother in an interracial union plays a role in shaping experiences of social support. Specifically, Bratter and Whitehead (2018) used data from the Fragile Families and Wellbeing Study (Reichman, Teitler, Garfinkel, \& McLanahan, 2001) collected at the 
child's birth and approximately one-year post-birth to compare perceived support of mothers in mixed-race and single-race dyads. Support was defined as whether the mother perceived they could count on someone if they needed financial, housing, or childcare support. They found that White mothers in MER relationships perceived less support after the birth of their child and perceived even less support one-year post-birth compared to White mothers whose infants had White fathers. Black and Latinx mothers in MER dyads did not report this same decline in support compared to mothers in MoER partnerships. This study did not address how fathers in MER unions perceive social support nor whether social support for one parent influences the other parent within these relationships; the current study seeks to address these gaps.

Research indicates that individuals from Latinx and Asian American backgrounds report a greater reliance on familial support compared to European Americans and African Americans (Haxton \& Harknett, 2009; Hogan, Eggebeen, \& Clogg, 1993; Kim \& McKenry, 1998; Taylor, Chatters, Woodward, \& Brown, 2013). Among these four cultural groups, African Americans maintained large social networks, but they were more likely to consist of friends, neighbors, or coworkers instead of family (Haxton \& Harknett, 2009; Kim \& McKenry, 1998; Uttal, 1999). These differences in cultural expectations and norms regarding the role of family support are likely to shape the ways in which support, or the lack thereof, affects coparental conflict among MER couples. Specifically, if an individual, or both individuals in the dyad, value family relationships but have been disconnected from that network they may be likely to have increased conflict and stress.

\section{Transition to Parenthood}


Research indicates that, on average, the transition to parenthood can have a negative effect on the quality of parents' relationships (Belsky, Spanier, \& Rovine, 1983; Keizer, Dykstra, \& Poortman, 2010; Medina, Lederhos, \& Lillis, 2009). For some, relationship quality decreases during this period because of the increased demands of parenthood, changes in the division of household labor (Yavorsky et al., 2015), decreased sleep (Medina et al., 2009), and change in the system from a dyad to a triad in which the focus is shifted from the dyad to the care of the baby.

\section{Multiethnoracial Dyads and the Transition to Parenthood}

Limited research has investigated how diverse families, characterized by race or ethnicity and social class, differentially experience the transition to parenthood (PerryJenkins \& Shoppe-Sullivan, 2019). Even less is known about the experiences of multiethnoracial (MER) couples. There are few studies about the experiences of MER parents and the transition to parenthood, and the few that exist focus on mothers' experiences during this time period, neglecting both fathers' experiences and possibly crossover partner effects (Roy, Mitchell, James, Miller, \& Hutchinson, 2019). Roy and colleagues (2019) conducted two semi-structured interviews and a focus group with twelve first-time mothers. Eight of the mothers were in biracial relationships, defined as "couples from different racial/ethnic backgrounds", and four of the mothers were in monoracial relationships (Roy et al., 2019). All mothers discussed the importance of support from their family. Mothers in biracial relationships described difficulties they experienced with their husband's family of origin with differences rooted in their cultural upbringing. Roy et al. (2019) found several points of conflict for young mothers in biracial relationships that were distinct from the experiences described by mothers in 
monoracial relationships. First, there were disagreements regarding discipline or how to respond to the fussiness of the baby. Second, mothers in MER relationships reported greater conflict around the division of household labor. Third, mothers in MER relationships experienced more stress in terms of micro- and macro-aggressions from family, friends, and people within the community which often led to a changed perspective of themselves, their partner, and their child.

This qualitative research highlights the added stress women in MER couples face across the transition to parenthood (Roy et al., 2019). In addition, these couples perceive that their conflict is arising from differences in cultural perspectives and upbringings (Crippen \& Brew, 2013; Edwards et al., 2009). Meanwhile, MER parents often have less support from their families than MoER parents. These additional stressors may explain the increased rates of dissolution among MER dyads compared to MoER dyads (Fu et al., 2001; Zhang \& Van Hook, 2009). The current study will explore the experience of MER parents compared to MoER parents during the transition to parenthood in a sample of 207 new parents with the aim of confirming preliminary themes in the literature that have emerged around parental conflict during new parenthood and to better understand the unique challenges MER families face.

\section{The Current Study}

The proposed study aims to examine differences in both levels of coparenting conflict as well as increases in coparenting conflict across the transition to parenthood for MER parents and MoER parents. A second aim is to examine the role of familial support as a possible mediator and moderator of the relationship between family racial composition (MER vs. MoER) and co-parenting conflict (Bratter \& Whitehead, 2018). 
Using data from a NIMH longitudinal study of 207 low-income parents experiencing the transition to parenthood, the present study will examine the following questions:

\section{Question 1}

What are the different compositions of multiethnoracial (MER) families and how do MER families differ from monoethnoracial (MoER) families on key demographic variables?

This question is descriptive and not hypothesis driven. Most studies conducted investigate the differences between MoER and MER families as two dichotomous groups. The current study will examine differences at this broader level but also, when possible, examine different types of MER families. Therefore, as a first step, this study provides a detailed breakdown of the different ethnoracial compositions of families by race and gender, and explores whether these families differ socioeconomically and along various other dimensions (i.e., number of children in the household, length of time living together).

\section{Question 2}

Is there a difference in the amount of parental conflict reported by mothers and fathers in MER and MoER relationships one-month and one-year postnatally?

It is expected that parents from differing racial or ethnic backgrounds will have higher levels of parenting conflict at baseline and will continue to have higher levels of parenting conflict one year after birth (Bhugun, 2017; Crippen \& Brew, 2013; Edwards et al., 2009).

\section{Question 3}


Do parents in MER relationships have greater increases in parental conflict over the transition to parenthood than parents in MoER relationships?

It is expected that parents in MER relationships will have greater increases in parental conflict from one-month to one-year postnatally compared to parents in MoER couples.

\section{Question 4}

Does social support moderate the relationship between family racial composition and co-parenting conflict?

Research suggests that social support buffers parental conflict for young parents, especially in families at greater risk for experiencing conflict (Ngai \& Ngu, 2014). It is hypothesized that social support will moderate the relationship between ethnoracial composition and parenting conflict. Specifically, social support will have a more salient role for MER dyads experiencing stress compared to MoER dyads since they are at greater risk for having the least access to support overall and the most isolated from social support networks.

\section{Question 5}

Does familial support mediate the relationship between family racial composition and co-parenting conflict?

The research demonstrating that MER dyads experience decreased levels of family support than their MoER counterparts (Bratter \& Whitehead, 2018) would suggest that familial support will mediate the relationship between family racial composition and coparenting conflict. It is predicted that MER dyads will perceive less social support than MoER dyads which will lead MER dyads to have greater levels of coparenting conflict 
across early parenthood. Partner effects (i.e., the effect of each partner's perceptions of social support on their partner's perceptions of conflict) were also explored since it is likely that partners' perspectives of social support likely influence the conflict the other partner experiences. 


\section{CHAPTER II}

\section{METHOD}

\section{Participants}

Participants for this study are part of the Work and Family Transitions Project, a larger longitudinal study of 207 diverse, low-income parents experiencing the transition to parenthood. Parents were recruited during their third trimester of pregnancy from prenatal education classes, prenatal clinics, local community centers, OB/GYN offices, and Women Infant and Children (WIC) offices primarily in Western Massachusetts and the surrounding communities. Couples were included if they met the following criteria: (a) they were in their third trimester of pregnancy, (b) both members were employed at least 20 hours per week and planned on returning to work within six months of the child's birth, and (c) they were "working" class defined by educational attainment of an Associate's degree or less and employment in an unskilled or semiskilled occupation. The current study's focus is on parental dyads, therefore single parents were excluded from the analysis. With the exclusion of single parents, the final sample was 142 dyads.

The median family income was $\$ 34,423$. There was a range in educational attainment levels. The majority of mothers $(51 \%)$ and fathers $(64 \%)$ held a high school or general equivalency diploma. While $40 \%$ of mothers in this sample had some type of vocational training or held a 1- or 2-year associate's degree, only $16 \%$ of fathers attained

the same level of educational. The sample was also racially/ethnically diverse for mothers (41\% White, 32\% Latina, 21\% African American/Black, 6\% Mixed/Multiracial) and fathers (37\% White, 31\% Latino, 27\% African American/Black, 5\% Mixed/Multiracial).

\section{Procedures}


Data collection began in 2003 and was completed in 2009. The proposed study will utilize data from four of the five phases of the project starting after the birth of the child. Only four phases, of the original five, were used since coparenting conflict was measured only after their child was born, similar to other research conducted with parents over the transition to parenthood (Schoppe-Sullivan \& Mangelsdorf, 2013; Van Egeren, 2004). Couples were interviewed separately in their homes by trained graduate students and data from the four time points used included: (a) Time 1: one-month postpartum, (b) Time 2: one month after returning to paid work (approximately 4 months postpartum), and (c) Time 3: a six-month mail-in survey, and (d) Time 4: one-year postpartum (See Figure 1). Since the current study only used four phases of the data, phases two through five will be from this point forward labeled as Time 1 through Time 4 .

\begin{tabular}{|c|c|c|c|c|c|}
\hline $\begin{array}{l}\text { Third } \\
\text { Trimester } \\
\text { of } \\
\text { Pregnancy }\end{array}$ & & $\begin{array}{c}\text { One } \\
\text { Month } \\
\text { Post- } \\
\text { partum }\end{array}$ & & $\begin{array}{c}\text { Six Months } \\
\text { Post- } \\
\text { partum }\end{array}$ & \\
\hline 0 & $\star$ & (1) & 2 & (3) & 4 \\
\hline & $\begin{array}{l}\text { Birth } \\
\text { of } \\
\text { Child }\end{array}$ & & $\begin{array}{c}\text { Return } \\
\text { to } \\
\text { Work }\end{array}$ & & $\begin{array}{c}\text { One Year } \\
\text { Post- } \\
\text { partum }\end{array}$ \\
\hline
\end{tabular}

Figure 1. An illustration of the study timeline. Phases two through five of the original study were used and are relabeled as Time 1 through 4 for the current study. In bold, are the four phases that were used.

\section{Measures}

\section{Demographics}

At baseline, both parents reported demographic information, including their relationship status (e.g., in a romantically stable relationship, in an on-again off-again relationship, just friends), their ethnic/racial identity, an estimate of their income, length 
of time they lived together prior to pregnancy, and the number of children living in the household.

Ethnoracial composition of each dyad was constructed using mothers' and fathers' reported racial or ethnic identity at baseline (third trimester of pregnancy). First, mothers' and fathers' racial and ethnic identity was matched. If their racial and ethnic identity was the same, the dyad was categorized as monoethnoracial (MoER). If their racial and ethnic identity were not the same, the dyad was categorized as multiethnoracial (MER).

\section{Co-parental Conflict}

The Co-parenting Conflict sub-scale from the Quality of Co-parental Communication scale (Ahrons, 1981) was used to assess interparental conflict. This measure was completed by both mothers and fathers at Time 1 through 4 . This subscale is made up of four items (e.g., "When you and your partner discuss parenting issues, how often does an argument result?" and "How often is the conversation stressful and tense?"). Items were rated on a five-point scale $(1=$ never to $5=$ always $)$. A total score was created by averaging the four items. Higher scores reflect higher conflict. Adequate internal consistency was found for the conflict (mothers $\alpha=.79-.85$; fathers $\alpha=.76-.86$ ) subscales.

\section{Family Social Support}

Family support was measured with an adapted version of the Perceived Social Support Scale - Family (Procidano \& Heller, 1983). For the current study, family support was measured at Time 1 . Mothers and fathers rated 20 statements regarding the degree of support they receive from family members. Items were rated on a four-point scale $(1=$ 
generally false, $2=$ more false than true, $3=$ more true than false, $4=$ generally true) . Sample items include, "Most other people are closer to their family than I am" and "There is a member of my family I could go to if I were just feeling down, without feeling funny about it later." A total score was created by averaging all the items. Higher scores reflect greater familial support. Adequate internal consistency was found for mothers $(\alpha=.71)$ and fathers $(\alpha=.76)$.

\section{Analytic Plan}

Descriptive statistics for all study variables were conducted. Any variables that were not normally distributed were transformed. Multilevel modeling (MLM) was used to investigate the research question and was facilitated by the Mplus 8.1 program (Muthén \& Muthén, 1998-2017). The assumptions of MLM that were checked were adequate sample size, homoscedasticity, normality, linearity, random missingness, and multicollinearity. To check the assumption of random missingness, the Little's MCAR test was evaluated. A non-significant chi-square statistic indicated that the pattern of missing data was random. Full information maximum likelihood was then acceptable to address missing data. This method retained all individuals who completed at least one measure of a study variable. Next, to identify univariate outliers, $z$-scores associated with minimum and maximum values on each of the predictors was assessed. Z-score values listed at or above 2.5 are univariate outliers. Multivariate outliers were evaluated using Mahalanobis $D^{2}$ in which identified cases with too large a value for their own group were considered multivariate outliers. There were no multivariate outliers detected.

Next, the assumptions of univariate and multivariate normality and linearity were assessed by examining normal and detrended normal Q-Q Plots, box and whiskers plots, 
histograms, and the ratios between skewness and skewness standard error. Multivariate normality was assessed using Mardia's normalized coefficient which indicates a violation of multivariate normality. Linearity was further assessed using bivariate scatterplots. Multicollinearity was assessed by examining a correlation matrix. Correlations exceeding .80 violate the assumption of multicollinearity. Furthermore, when examining collinearity diagnostics, no value should exceed 30. The assumptions were evaluated through SPSS 24.0 (IBM Corp, 2016). Family support and coparenting conflict were both transformed due to issues of skewness and kurtosis. All other assumptions were met.

MLM addresses dependencies in the data due to repeated measures over time and allows for the simultaneous examination of both levels of and changes in coparental conflict in new parenthood. Specifically, two-level models were used to estimate withinperson change over time at level 1 and between-person differences at level 2. Thus, this analytic technique allowed for the examination of both interindividual differences and intraindividual change. Additionally, MLM adjusts for dependency in the data due to the additional nesting of individuals within dyads. Specifically, longitudinal dyadic multilevel models (Kenny, Kashy, \& Cook, 2006) were used to allow for simultaneous estimation of conflict level and change for both dyad members, while accounting for the correlation between parents' perceived levels of conflict.

A series of models were fit to the data using this general multilevel dyadic framework. First, the unconditional model determined the trajectory of each individual parent while accounting for dyadic interdependence, which are assumed to vary randomly across individuals. Next, the conditional models were built from the best-fitting growth curve model by adding specific predictor variables (i.e., family ethnoracial composition 
and both parents' reports of family support at T1) that could explain between-person differences in both levels of (i.e., the intercept) and change in coparental conflict over time (i.e., the slope) perceived by each partner.

To test the second research question, two separate two level models were run. In the first, time was centered at Time 1 (one-month post-birth). Thus, the intercept (i.e., the value of the outcome variable when all predictors are equal to zero) reflects the level of conflict right after the child's birth. This tests whether there are significant differences in parental conflict at baseline (approximately one-month post-birth) between mono(MoER) and multi-ethnoracial (MER) families. In the second model, time was recentered at one-year post-birth, which tests whether MoER and MER families significantly differ in levels of conflict at the final time point. It was expected that there would be a significant difference at the intercept at both time points between these two groups such that MER parents would have greater reported levels of conflict, as perceived by both parents, than MoER parents. Represented in standard MLM notation, the model for the c path (i.e., the association between coparenting conflict and ethnoracial composition) was as follows:

Level 1

$$
\text { Conflict }_{i j}=\beta_{0 j}+\beta_{1 j} *\left(\text { Time }_{i j}\right)+e_{i j}
$$

Level 2

$$
\begin{aligned}
& \beta_{0 j}=\gamma_{00}+\gamma_{01} *\left(\mathrm{ERC}_{\mathrm{j}}\right)+\mathrm{r}_{0 j} \\
& \beta_{1 j}=\gamma_{10}+\mathrm{r}_{1 j}
\end{aligned}
$$

To test the third question of whether MER parents have greater increases in parental conflict during early parenthood compared to MoER parents, the average growth 
trajectories from Time 1 through 4 for these two groups was examined. As noted, MLMs quantify the linear rate of change per unit of time, as well as individual variations around the average growth trajectory. It was expected that the rate of change for MER parents would differ compared to MoER parents such that MER families would have a steeper slope or greater increase in conflict per unit of time. Represented in standard MLM notation, the model for the c path (i.e., the association between change in coparenting conflict and ethnoracial composition) was as follows:

Level 1

$$
\text { Conflict }_{i j}=\beta_{0 j}+\beta_{1 j} *\left(\text { Time }_{i j}\right)+e_{i j}
$$

Level 2

$$
\begin{aligned}
& \beta_{0 j}=\gamma_{00}+\mathrm{r}_{0 j} \\
& \beta_{1 j}=\gamma_{10}+\gamma_{11} *\left(\mathrm{ERC}_{\mathrm{j}}\right)+\mathrm{r}_{1 j}
\end{aligned}
$$

To test my third question of whether social support (Time 1, one month post birth) moderates the relationship between family ethnoracial composition and coparenting conflict, additional between-person predictors (family support and the interaction of family support and family ethnic compositions) of parenting conflict level (intercept) and change (slope) were added to the model. It was expected that social support would reduce conflict for all families, however, it would have a stronger effect for MER families. In the context of high family support, coparenting conflict would more greatly decrease in MER families. By contrast, in the context of low family support, it was expected that parental conflict would be magnified in MER families compared to MoER families. Represented in standard MLM notation, the model for the interaction between family support and ethnoracial composition coparenting conflict was as follows:

Level-1 Model

$$
\text { Conflict }_{i j}=\beta 0_{j}+\beta_{1 j} *\left(\text { Time }_{i j}\right)+e_{i j}
$$


Level-2 Model

$$
\begin{aligned}
& \beta_{0 j}=\gamma_{00}+\gamma_{01} *\left(\mathrm{ERC}_{j}\right)+\gamma_{02} *\left(\mathrm{MFS}_{j}\right)+\gamma_{03} *\left(\mathrm{FFS}_{j}\right)+\gamma_{04} *\left(\mathrm{ERC}_{i j}\right) *\left(\mathrm{MFS}_{i j}\right)+ \\
& \gamma_{05} *\left(\mathrm{ERC}_{i j}\right) *\left(\mathrm{FFS}_{i j}\right)+\mathrm{r}_{0 j} \\
& \beta_{1 j}=\gamma_{10}+\gamma_{11} *\left(\mathrm{ERC}_{j}\right)+\gamma_{12} *\left(\mathrm{MFS}_{j}\right)+\gamma_{13} *\left(\mathrm{FFS}_{j}\right)+\gamma_{14} *\left(\mathrm{ERC}_{i j}\right) *\left(\mathrm{MFS}_{i j}\right)+ \\
& \gamma_{15} *\left(\mathrm{ERC}_{i j}\right) *\left(\mathrm{FFS}_{i j}\right)+\mathrm{r}_{1 j}
\end{aligned}
$$

Finally, to test my last research question of whether social support (Time 1)

mediates the relationship between ethnoracial composition and coparenting conflict over the transition to parenthood multilevel structural equation modeling was used (MLSEM; Preacher, Zyphur, Zhang, 2010). Based on the article by Bratter and Whitehead (2018), it was expected that MER families would perceive lower family support than monoethnoracial families (i.e., the "a" path), which, in turn, would lead to higher coparental conflict (i.e., the "b" path). MLSEM was used because it allows for the inclusion of multiple outcome variables (which are always present in mediation) and accounts for the interdependencies of longitudinal and dyadic data. Next, given that the mediator (social support) and the outcome variable (parental conflict) were both measured dyadically, the model simultaneously accounted for the correlation between parents' reports of both the mediator and the outcome. For each dyad member, the key test of the mediational hypothesis was whether the indirect effect of family ethnoracial composition on parental conflict was mediated through each parents' report of family support. All models accounted for the direct effect of family ethnoracial composition on conflict to ensure a valid test of the mediational process (the indirect effect) (Hayes, 2017). Represented in standard MLM notation, the model for the indirect effect of ethnoracial composition on parental conflict through family support was as follows:

\section{Level-1 Model}

$$
\text { Conflict }_{i j}=\beta 0_{j}+\beta_{1 j} *\left(\text { Time }_{i j}\right)+e_{i j}
$$


Level-2 Model

$$
\begin{aligned}
& \beta_{0 j}=\gamma_{00}+\gamma_{01} *\left(\mathrm{ERC}_{j}\right)+\gamma_{02} *\left(\mathrm{MFS}_{j}\right)+\gamma_{03} *\left(\mathrm{FFS}_{j}\right)+\mathrm{r}_{0 j} \\
& \beta_{1 j}=\gamma_{10}+\gamma_{11} *\left(\mathrm{ERC}_{j}\right)+\gamma_{12} *\left(\mathrm{MFS}_{j}\right)+\gamma_{13} *\left(\mathrm{FFS}_{j}\right)+\mathrm{r}_{1 j}
\end{aligned}
$$

Represented in standard MLM notation, the model for the a paths (the association between family support and ethnoracial composition for mothers and fathers) were as follows:

$$
\begin{aligned}
& \operatorname{MFS}_{i j}=\beta_{0 j}+\beta_{1 j} *\left(\mathrm{ERC}_{i j}\right)+e_{i j} \\
& \mathrm{FFS}_{i j}=\beta_{0 j}+\beta_{1 j} *\left(\mathrm{ERC}_{i j}\right)+e_{i j}
\end{aligned}
$$

Finally, given that indirect (mediational) effects are typically not normally distributed, Bayesian estimation in Mplus was used, because it does not assume normality, but instead provides the entire distribution for estimates (i.e., posterior distributions; Muthén \& Asparouhov, 2012). Based on these posterior distributions, 95\% credible intervals (CIs) were generated, which indicated that a $95 \%$ chance that the interval contained the true estimate. Thus, $95 \%$ CIs that do not contain zero were considered significant.

\section{Partner Effects}

Since both partners' perspectives of social support likely influence the conflict perceptions of their partners, we also explored Actor Partner Interdependence Models (APIM; Cook \& Kenny, 2005) to test for partner effects in all models. More specifically, APIM allowed for the simultaneous estimation of actor effects (i.e., the effect each person's perceptions of social support on his/her own perceptions of conflict) and partner effects (i.e., the effect of each dyad member's partner's perceptions of social support on his/her own perceptions of conflict). 


\section{CHAPTER III}

\section{RESULTS}

\section{Descriptive Statistics}

Prior to examining differences in conflict between monoethnoracial (MoER) and multiethnoracial (MER) parent dyads, we first examined the racial and ethnic composition (see Table 1), as well as various sociodemographic characteristics of these dyads (see Tables 2).

\section{Table 1}

Breakdown of Multiethnoracial and Monoethnoracial Couples

\begin{tabular}{|c|c|c|}
\hline & \\
\hline & $N$ & $\%$ \\
\hline \multicolumn{3}{|l|}{ Monoethnoracial $(N=92)$} \\
\hline White & 38 & $41 \%$ \\
\hline Latino & 29 & $32 \%$ \\
\hline Black & 25 & $27 \%$ \\
\hline \multicolumn{3}{|c|}{ Multiethnoracial $(N=50)$ (female-male) } \\
\hline White-Latino & 14 & $27 \%$ \\
\hline White-Black & 4 & $8 \%$ \\
\hline White-Multiracial & 2 & $4 \%$ \\
\hline Latina-White & 3 & $6 \%$ \\
\hline Latina-Black & 11 & $21 \%$ \\
\hline Latina-Multiracial & 3 & $6 \%$ \\
\hline Black-White & 2 & $4 \%$ \\
\hline Black-Latino & 1 & $2 \%$ \\
\hline Black-Multiracial & 1 & $2 \%$ \\
\hline Multiracial-White & 1 & $2 \%$ \\
\hline Multiracial-Latino & 2 & $4 \%$ \\
\hline Multiracial-Black & 5 & $10 \%$ \\
\hline Multiracial-Multiracial & 1 & $2 \%$ \\
\hline
\end{tabular}

Note. MER dyads are organized by mother race first followed by father race 
In our sample, 17 variations in parents' ethnoracial composition were found. Sixty-four percent of parent dyads were MoER (i.e., parents from the same racial or ethnic background), while the remaining thirty-six percent of parent dyads were MER. A majority of the couples fell into either Latinx and White dyads (33\%), Latinx and Black dyads (23\%), or Black and White dyads (12\%). The number of dyads that include one White parent and one parent of color $(n=26)$ are about equal to the number of dyads with two parents of color $(n=25)$.

\section{Table 2}

Participant Demographics by Ethnoracial Category

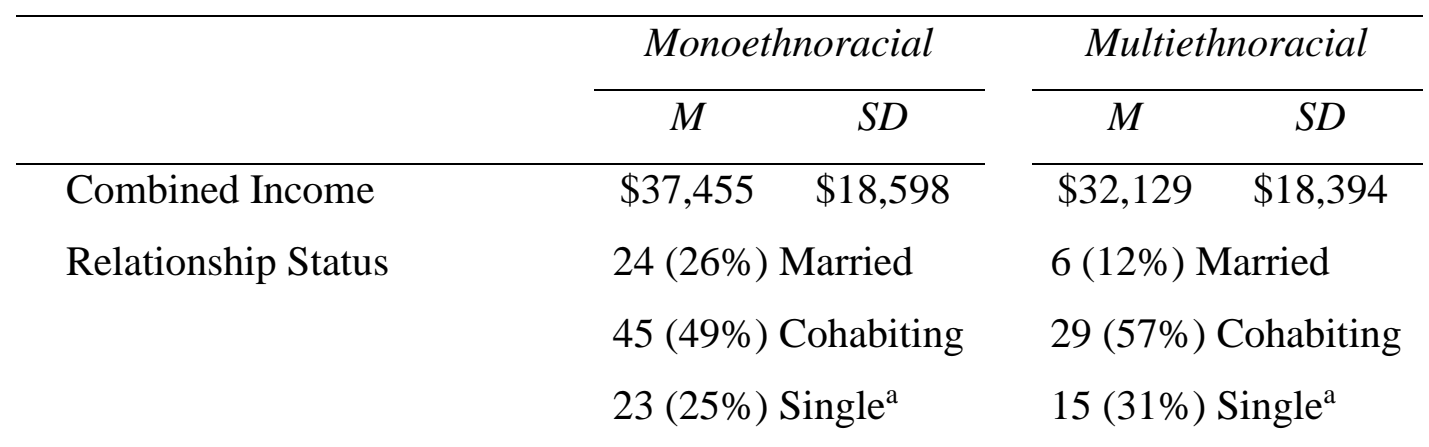

Mothers

$\begin{array}{lcccc}\text { Age } & 25.36 & 4.87 & 25.67 & 5.91 \\ \text { Weeks of Parental Leave } & 10.75 & 7.70 & 8.11 & 4.88 \\ \text { Number of Kids in Household } & 0-42(46 \%) & 0-18(37 \%) & \\ & 1-22(24 \%) & & 1-12(25 \%) \\ & 2-18(19 \%) & 2-9(18 \%) & \\ & 3-9(10 \%) & 3-8(16 \%) & \\ & 4-1(1 \%) & & 4-2(4 \%) & \\ \text { Education } & N & \% & N & \% \\ \text { Less than High School } & 9 & 10 & 4 & 8 \\ \text { High School } & 45 & 49 & 27 & 54 \\ \text { Associate's } & 38 & 41 & 19 & 38\end{array}$


Bachelor's

Fathers

Age

27.86

6.14

27.53

6.25

Number of Kids in Household

$$
\begin{aligned}
& 0-45(62 \%) \\
& 1-15(21 \%) \\
& 2-9(12 \%) \\
& 3-4(5 \%) \\
& 4-0(0 \%)
\end{aligned}
$$

$0-20(52 \%)$

1 - $5(13 \%)$

2 - $6(15 \%)$

$3-6(15 \%)$

$4-2(5 \%)$

Education

Less than High School

High School

Associate's

Bachelor's
N

14

47

14

1

$\%$

$14 \quad 19$

$\begin{array}{ll}47 & 61\end{array}$

19

1
N

9

27

4

Note. No differences were found between MER and MoER dyads in any of the reported participant demographics for both mothers and fathers. ${ }^{\text {a }}$ Single $=$ not married and not living together. However, all dyads were involved in romantic relationships having categorized themselves as either "romantically involved on a steady basis" or in an "on-again off-again" relationship.

There was a trend that mothers in MoER dyads are more likely to be married than mothers in MER dyads; $F(1,158)=3.05, p=.08$. When mothers were married, however, MER parents $(M=6.19$ years $)$ were married for longer than their MoER counterparts $(M$ $=2.70$ years $), F(1,29)=5.82, p=.02$.

Ethnoracial composition is significantly related to the number of children in the household for fathers, where fathers in MER dyads $(M=1.18)$ live with more children in their household than fathers in MoER dyads $(M=0.64) ; F(1,118)=6.30, p=.01$. Fathers in MER dyads are also less likely to be married than MoER dyads, $F(1,118)=$ 4.67, $p=.03$, but when married are also married for more years on average (MER $M=$ 7.20 years; MoER $M=2.52$ years), $F(1,25)=8.41, p=.01$. 
Of interest and not hypothesis driven, mothers in MER dyads $(M=8.22)$ have significantly shorter weeks of parental leave after their babies are born, compared to mothers in MoER dyads $(M=10.58) ; F(1,139)=3.94, p=.04$, which may be of importance when looking at coparenting conflict after mothers return to work.

Table 3 presents descriptive statistics for mothers' and fathers' average family support across the transition to parenthood, in addition to coparenting conflict over the five time points of measurement. There were no differences found between mothers' and fathers' reported family support and coparenting conflict.

\section{Table 3}

Descriptive Statistics for Mothers' and Fathers' Family Support and Coparenting Conflict by Ethnoracial Composition

\begin{tabular}{|c|c|c|c|c|c|c|}
\hline & \multicolumn{3}{|c|}{ Monoethnoracial } & \multicolumn{3}{|c|}{ Multiethnoracial } \\
\hline & $N$ & $M$ & $S D$ & $N$ & $M$ & $S D$ \\
\hline \multicolumn{7}{|l|}{ Mothers } \\
\hline Family Support T1 & 89 & 3.29 & .54 & 44 & 3.07 & .58 \\
\hline Coparenting Conflict T1 & 88 & 1.91 & 67 & 35 & 2.17 & .69 \\
\hline Coparenting Conflict T2 & 81 & 2.21 & .81 & 39 & 2.37 & .87 \\
\hline Coparenting Conflict T3 & 57 & 2.20 & .81 & 32 & 2.37 & .71 \\
\hline Coparenting Conflict T4 & 66 & 2.26 & .72 & 35 & 2.37 & .78 \\
\hline \multicolumn{7}{|l|}{ Fathers $^{\mathrm{a}}$} \\
\hline Family Support T1 & 57 & 3.23 & .50 & 25 & 3.14 & .54 \\
\hline Coparenting Conflict T1 & 65 & 2.07 & .62 & 29 & 2.12 & .70 \\
\hline Coparenting Conflict T2 & 66 & 2.31 & .81 & 33 & 2.36 & .85 \\
\hline Coparenting Conflict T3 & 37 & 2.15 & .70 & 14 & 2.23 & .83 \\
\hline Coparenting Conflict T4 & 53 & 2.29 & .74 & 25 & 2.37 & .75 \\
\hline
\end{tabular}


Table 4 presents correlation data between sociodemographic information about the parent dyads, family support, and coparenting conflict. Mothers reported higher family support if they had fewer children living in their household $(r(140)=-.18, p=$ $.03)$, and lower levels of anxiety $(r(141)=-.20, p=.02)$ and depression $(r(140)=-.29, p$ $<.001)$. In contrast, none of the demographic variables were significantly related to family support for fathers.

One-month after the baby was born, mothers with higher education $\left(r_{t l}(120)=\right.$ $.23, p=.01)$ reported higher coparenting conflict. Mothers with greater depression $\left(r_{t 1}\right.$ $\left.(120)=.23, p=.01 ; r_{t 2}(119)=.23, p=.01\right)$ and anxiety $\left(r_{t 1}(120)=.19, p=.04 ; r_{t 2}(118)\right.$ $=.31, p<.001)$ had greater conflict with their coparents one-month post-partum and after their return to work. When mothers returned to work, those with more children in their household reported higher coparenting conflict $\left(r_{t 2}(118)=.22, p=.02\right)$. On the other hand, at one-month and one-year postpartum younger fathers reported higher levels of coparenting conflict $\left(r_{t 1}(92)=-.21, p=.04 ; r_{t 4}(75)=-.23, p=.04\right)$. Fathers with more children living in their household reported greater conflict with their coparents onemonth postpartum $\left(r_{t l}(91)=-.24, p=.02\right)$. Additionally, fathers who had lived with their partners for less time $\left(r_{t 2}(98)=-.28, p<.01 ; r_{t 3}(51)=-.30, p=.03 ; r_{t 4}(78)=-.40, p<\right.$ $.001)$ as well as fathers with greater depression $\left(r_{t 2}(94)=.23, p=.03 ; r_{t 3}(49)=.32, p=\right.$ $\left..03 ; r_{t 4}(71)=.43, p<.001\right)$ reported higher levels of conflict from the time mothers returned to work through one year postpartum. 


\section{Table 4}

Relationships Between Covariates and Outcome Variables

\begin{tabular}{|c|c|c|c|c|c|c|c|c|c|c|}
\hline \multirow[b]{3}{*}{ Variables } & \multicolumn{5}{|c|}{ Mothers $(n=142)$} & \multicolumn{5}{|c|}{ Fathers $(n=115)$} \\
\hline & \multirow[b]{2}{*}{$\begin{array}{l}\text { Family } \\
\text { Support }\end{array}$} & \multicolumn{4}{|c|}{ Coparenting Conflict } & \multirow[b]{2}{*}{$\begin{array}{l}\text { Family } \\
\text { Support }\end{array}$} & \multicolumn{4}{|c|}{ Coparenting Conflict } \\
\hline & & Time 1 & Time 2 & Time 3 & Time 4 & & Time 1 & Time 2 & Time 3 & Time 4 \\
\hline \multicolumn{11}{|l|}{ Demographics } \\
\hline Age & -.05 & .15 & -.06 & .01 & .01 & -.01 & $-.21 *$ & $-.18 \dagger$ & .09 & $-.23 *$ \\
\hline Number of Kids in Household & $-.18^{*}$ & .08 & $.22 *$ & -.06 & $.18 \dagger$ & -.09 & $-.24 *$ & -.11 & -.03 & -.10 \\
\hline Time Living Together & .03 & .002 & -.07 & -.09 & .01 & .03 & $-.18 \dagger$ & $-.28 * *$ & $-.30 *$ & $-.40 * * *$ \\
\hline Education Level & .03 & $.23 *$ & .01 & $.19 \dagger$ & $.20 \dagger$ & -.05 & .01 & .04 & -.13 & -.03 \\
\hline Combined Family Income & $.14 \dagger$ & .08 & -.09 & .04 & -.02 & $.14 \dagger$ & -.17 & $-.17 \dagger$ & -.08 & $-.21 \dagger$ \\
\hline Weeks of Leave & .09 & -.15 & -.08 & -.18 & -.10 & - & - & - & - & - \\
\hline Family Support & - & -.10 & $-.29 * *$ & -.18 & -.16 & - & -.06 & -.07 & .01 & -.18 \\
\hline
\end{tabular}

Note. $\uparrow \mathrm{p}<.10 * p<.05 . * * p<.01 . * * * \mathrm{p}<.001$. 


\section{Co-parental Conflict in Multiethnoracial and Monoethnoracial Parent Dyads}

\section{Total Effects Models: Levels}

To test the first research question, two separate two-level models were fit to the data. In the first, time was centered at Time 1 (one-month post-birth). In the second, time was re-centered at Time 4, one-year post-birth. It was expected that there would be a significant difference at the intercept at both time points between these two groups such that MER parents would have greater levels of coparenting conflict than MoER parents.

As expected, for mothers the ethnoracial composition of the dyad was positively associated with coparenting conflict one-month postpartum $(B=0.08,95 \% C I=[0.01$, $0.15], p=.02)$, and marginally associated at one-year $(B=0.08,95 \% C I=[-0.01,0.14], p$ $=.05)$ after the birth. As seen in Figure 2 , mothers in MER dyads $\left(M_{\text {month }}=1.96 ; M_{\text {year }}=\right.$ 2.28) reported greater coparenting conflict than mothers in MoER dyads $\left(M_{\text {month }}=1.74\right.$; $\left.M_{\text {year }}=2.04\right)$. For fathers, however, ethnoracial composition was not related to coparenting conflict at one-month $(B=0.05,95 \% C I=[-0.02,0.11], p=.18)$ nor at oneyear $(B=0.05,95 \% C I=[-0.02,0.12], p=.24)$ after the birth of the child. See Models 1 and 2 of Table 5 for a report of the unstandardized associations from this model.

\section{Total Effects Models: Change}

To test the second question of whether MER parents have greater increases in parental conflict during early parenthood compared to MoER parents, the average growth trajectories for these two groups were examined. It was expected that parents in MER families would have a steeper increase in conflict than parents in MoER couples. Contrary to what was hypothesized, analyses revealed mothers in MER families had less of an increase in coparenting conflict than mothers in MoER families $(B=-0.03,95 \% C I$ $=[-0.05,-0.001], p=.03)$, and there was no difference in change in coparenting conflict 
for fathers based on ethnoracial composition $(B=-0.01,95 \% C I=[-0.04,0.02], p=.65)$.

See Model 3 of Table 5 for a report of the unstandardized associations from this model.

Table 5

Unstandardized Associations Between Ethnoracial Composition on Mothers and Fathers Coparenting Conflict

\begin{tabular}{|c|c|c|c|c|}
\hline \multirow[b]{2}{*}{ Model } & \multicolumn{2}{|c|}{ Mothers } & \multicolumn{2}{|c|}{ Fathers } \\
\hline & $\begin{array}{c}\text { Coefficient } \\
(S D)\end{array}$ & $95 \% C I$ & $\begin{array}{c}\text { Coefficient } \\
(S D)\end{array}$ & $95 \% C I$ \\
\hline \multicolumn{5}{|l|}{ Model 1 -Centered at Time 1} \\
\hline Baseline Coparenting Conflict & $1.32(0.04)^{*}$ & {$[1.24,1.39]$} & $1.37(0.03) *$ & {$[1.31,1.44]$} \\
\hline ERC $\rightarrow$ Coparenting Conflict & $0.08(0.03)^{*}$ & {$[0.03,0.16]$} & $0.05(0.04)$ & {$[-0.02,0.11]$} \\
\hline \multicolumn{5}{|l|}{ Model 2 - Centered at Time 4} \\
\hline Baseline Coparenting Conflict & $1.43(0.04)^{*}$ & {$[1.34,1.50]$} & $1.42(0.04)^{*}$ & {$[1.36,1.49]$} \\
\hline ERC $\rightarrow$ Coparenting Conflict & $0.08(0.04)^{*}$ & {$[-0.01,0.14]$} & $0.05(0.04)$ & {$[-0.02,0.12]$} \\
\hline \multicolumn{5}{|l|}{ Model 3-Slope } \\
\hline Baseline Coparenting Conflict & $1.52(0.03)^{*}$ & {$[1.48,1.57]$} & $1.52(0.03)^{*}$ & {$[1.47,1.58]$} \\
\hline$\Delta$ Coparenting Conflict & $0.06(0.02)^{*}$ & {$[0.04,0.10]$} & $0.03(0.01)^{*}$ & {$[0.00,0.05]$} \\
\hline ERC $\rightarrow \Delta$ Coparenting Conflict & $-0.03(0.02)$ & {$[-0.05,-0.001]$} & $-0.01(0.02)$ & {$[-0.04,0.02]$} \\
\hline
\end{tabular}

Note. ERC = Ethnoracial composition of dyad. Mothers' and fathers' coparenting conflict were correlated in each of the models. Each model controlled for number of kids in the household. $\dagger p<.10 *$ indicates that the $95 \%$ Bayesian CI does not include zero.

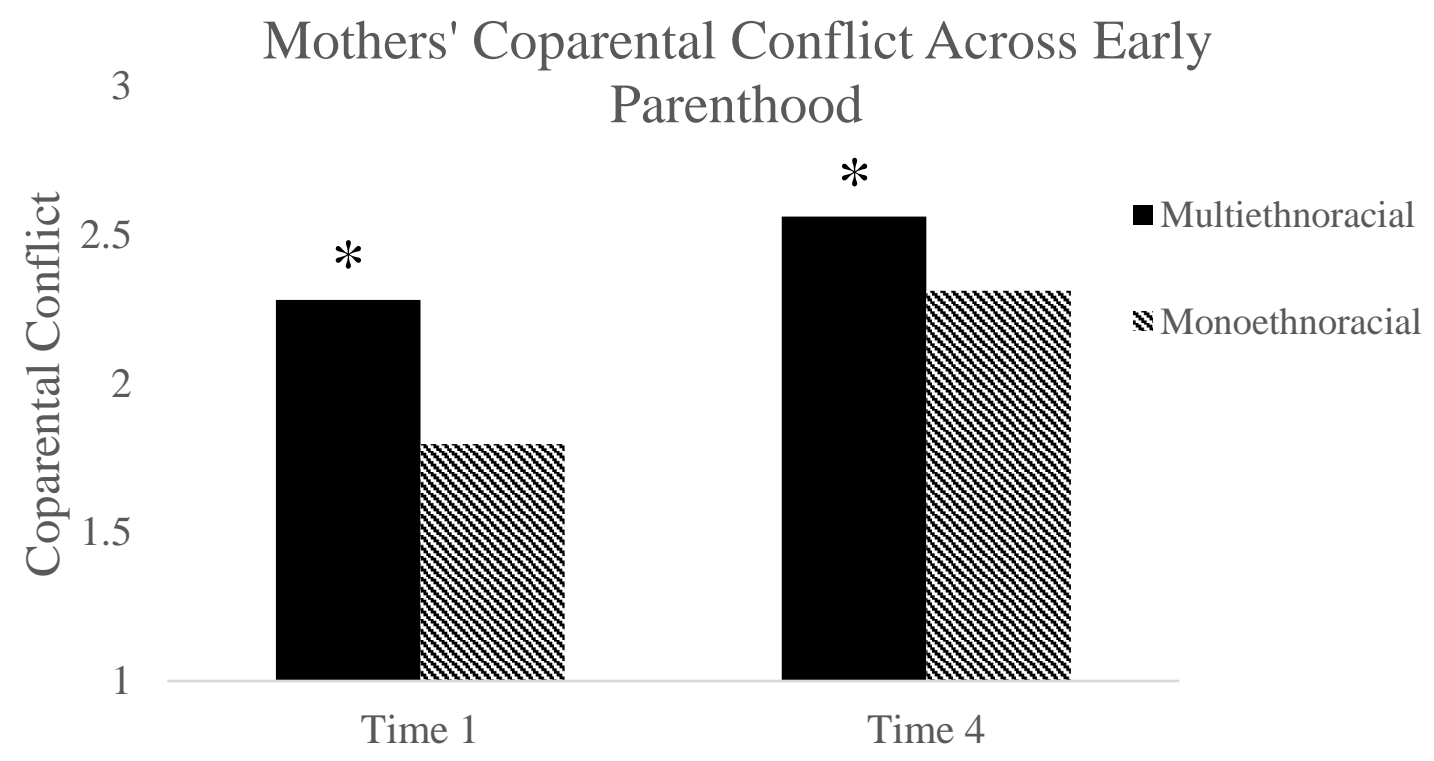

Figure 2. The figure illustrates differences in coparenting conflict across time for mothers in MoER and MER parent dyads. 


\section{Moderation Models}

Next, social support was examined as a moderator of the relationship between couple ethnoracial composition and co-parenting conflict over the transition to parenthood. It was hypothesized that under conditions of high family support, the negative relationship between couple ethnoracial composition and parental conflict would decrease more for parents in MER versus MoER families.

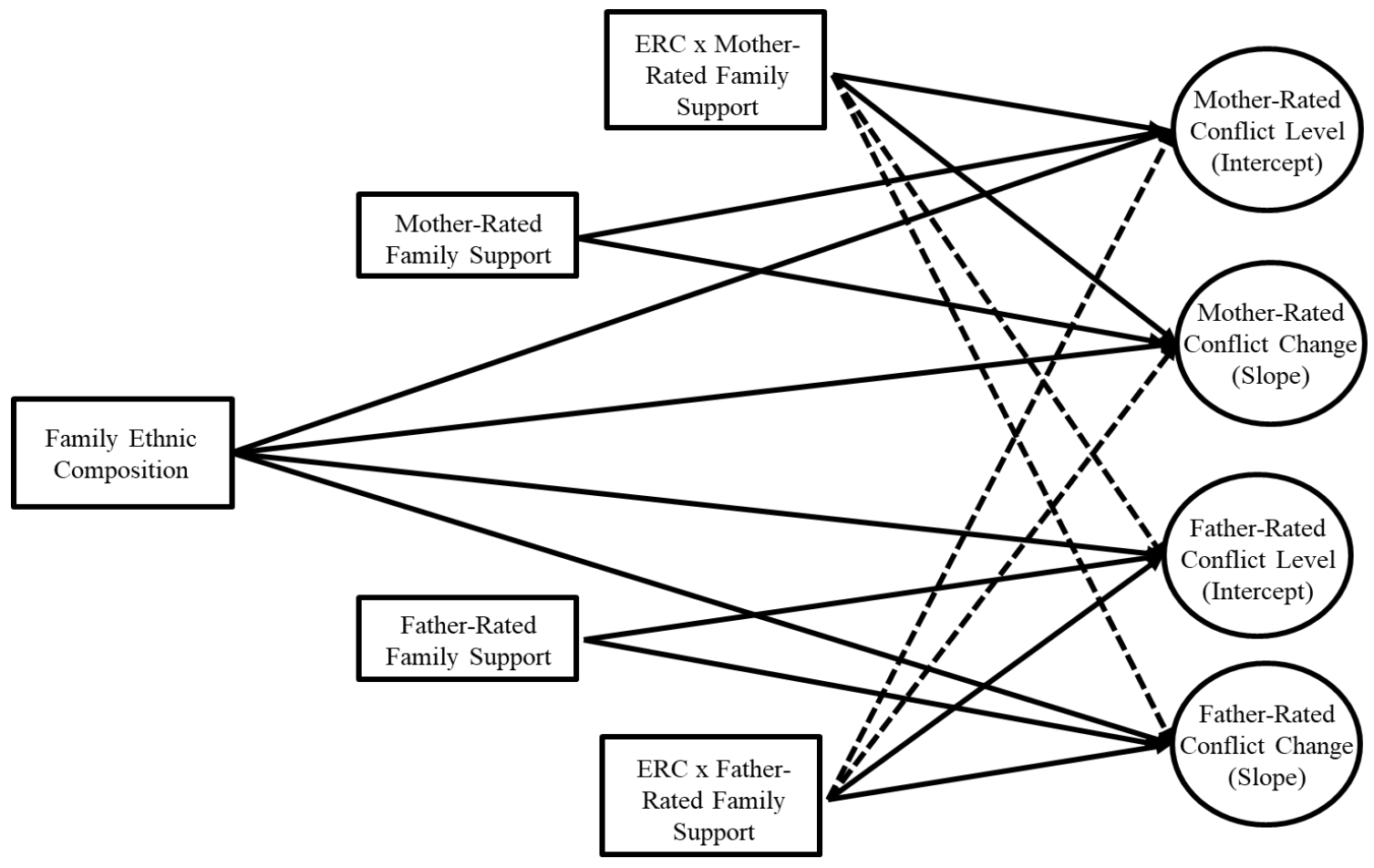

Figure 3. The hypothesized moderation model in which the interaction of family ethnoracial composition and family support predicts the level and change in coparenting conflict. For simplicity, only the partner effects for the interaction are depicted, however the model does also estimate the main partner-effects.

Contrary to what was expected, ethnoracial composition and family support did not interact to predict levels of coparenting conflict one month $(B=-0.01,95 \% C I=[-$ $0.04,0.02], p=.53)$ nor one-year $(B=-0.01,95 \% C I=[-0.05,0.02], p=.33)$ after the birth of the child for mothers. Similarly, ethnoracial composition and family support did not interact to predict coparenting conflict one-month postpartum $(B=-0.03,95 \% C I=[-$ 
$0.07,0.01], p=.13)$, nor one-year postpartum $(B=-0.02,95 \% C I=[-0.06,0.03], p=.46)$ for fathers.

Ethnoracial composition and family support also did not interact to predict changes in coparenting conflict across the transition to parenthood for mothers $\left(B_{\text {month }}=\right.$ $\left.0.001,95 \% C I=[-0.01,0.01], p=.92 ; B_{\text {year }}=-0.003,95 \% C I=[-0.02,0.01], p=.58\right)$ nor fathers $\left(B_{\text {month }}=0.003,95 \% C I=[-0.01,0.03], p=.58 ; B_{\text {year }}=0.001,95 \% C I=[-\right.$ $0.01,0.02], p=.86)$ at either one-month or one-year postpartum.

Given the small group sizes in the current sample, the predicted model may be overly complex, creating estimation problems in the model and possibly limiting results. To address this problem, parsimonious models may help to test the theory-guided hypotheses set forth without pathways that did not add meaningful significance to the model (Goodboy \& Kline, 2017). Thus, the model was simplified with a posteriori trimming of such pathways. The main effect of mothers' family support on coparenting conflict and the interaction between ethnoracial composition and mothers' family support were removed.

In this new, trimmed model a cross-over effect emerged with a significant interaction between mothers' family support and couples' ethnoracial match predicting fathers' coparenting conflict. Specifically, as shown in Figure 4, mothers' high family support served as a buffer for fathers' coparenting conflict at Time $1(B=0.02,95 \% C I=$ $[0.002,0.04], p=.04)$ in MoER families but not MER families. There was a trend for this same relationship for fathers coparenting conflict 1-year postpartum as well $(B=0.02$, 95\% $C I=[-0.002,0.04], p=.10)$. See Model 2 of Tables 6 and 7 for a report of the unstandardized associations from these models. 


\section{Table 6}

Unstandardized Interaction Between Ethnoracial Composition and Family Support at T1

\begin{tabular}{|c|c|c|c|c|}
\hline \multirow[b]{2}{*}{ Model } & \multicolumn{2}{|c|}{ Model 1 (Original Model) } & \multicolumn{2}{|c|}{ Model 2 (Final Model) } \\
\hline & Coefficient $(S D)$ & $95 \% C I$ & Coefficient $(S D)$ & $95 \% C I$ \\
\hline \multicolumn{5}{|l|}{ Mothers } \\
\hline ERC $\rightarrow$ Conflict & $0.08(0.05) \dagger$ & {$[-0.01,0.17]$} & $0.08(0.04) \dagger$ & {$[-0.01,0.14]$} \\
\hline MFS $\rightarrow$ Conflict & $-0.001(0.01)$ & {$[-0.02,0.02]$} & - & - \\
\hline FFS $\rightarrow$ Conflict & $-0.004(0.01)$ & {$[-0.02,0.02]$} & - & - \\
\hline ERC $x$ MFS $\rightarrow$ Conflict & $-0.01(0.01)$ & {$[-0.04,0.02]$} & - & - \\
\hline ERC x FFS $\rightarrow$ Conflict & $-0.02(0.02)$ & {$[-0.05,0.01]$} & - & - \\
\hline ERC $\rightarrow \Delta$ Conflict & $-0.02(0.02)$ & {$[-0.05,0.02]$} & - & - \\
\hline MFS $\rightarrow \Delta$ Conflict & $-0.001(0.003)$ & {$[-0.01,0.01]$} & - & - \\
\hline FFS $\rightarrow \Delta$ Conflict & $-0.002(0.003)$ & {$[-0.01,0.01]$} & - & - \\
\hline ERC x MFS $\rightarrow \Delta$ Conflict & $0.001(0.01)$ & {$[-0.01,0.01]$} & - & - \\
\hline ERC $x$ FFS $\rightarrow \Delta$ Conflict & $0.01(0.01)$ & {$[-0.01,0.02]$} & - & - \\
\hline Mean Coparenting Conflict & $1.32(0.05)^{*}$ & {$[1.22,1.41]$} & $1.33(0.04)^{*}$ & {$[1.26,1.40]$} \\
\hline$\Delta$ Coparenting Conflict & $0.05(0.02)^{*}$ & {$[0.02,0.09]$} & - & - \\
\hline \multicolumn{5}{|l|}{$\underline{\text { Fathers }}$} \\
\hline ERC $\rightarrow$ Conflict & $0.03(0.05)$ & {$[-0.08,0.13]$} & $0.04(0.04)$ & {$[-0.03,0.13]$} \\
\hline FFS $\rightarrow$ Conflict & $-0.02(0.01)^{*}$ & {$[-0.04,-0.01]$} & $-0.02(0.01)^{*}$ & {$[-0.03,-0.01]$} \\
\hline MFS $\rightarrow$ Conflict & $-0.01(0.01)$ & {$[-0.03,0.01]$} & $-0.01(0.01)$ & {$[-0.02,0.003]$} \\
\hline ERC x FFS $\rightarrow$ Conflict & $-0.03(0.02)$ & {$[-0.07,0.01]$} & $-0.01(0.01)$ & {$[-0.04,0.01]$} \\
\hline ERC $x$ MFS $\rightarrow$ Conflict & $-0.02(0.02)$ & {$[-0.01,0.05]$} & $0.02(0.01)^{*}$ & {$[0.002,0.04]$} \\
\hline ERC $\rightarrow \Delta$ Conflict & $0.004(0.02)$ & {$[-0.03,0.06]$} & - & - \\
\hline FFS $\rightarrow \Delta$ Conflict & $0.002(0.004)$ & {$[-0.01,0.01]$} & - & - \\
\hline MFS $\rightarrow \Delta$ Conflict & $-0.001(0.003)$ & {$[-0.01,0.01]$} & - & - \\
\hline ERC $x$ FFS $\rightarrow \Delta$ Conflict & $0.003(0.01)$ & {$[-0.01,0.03]$} & - & - \\
\hline ERC $\mathrm{x}$ MFS $\rightarrow \Delta$ Conflict & $-0.001(0.01)$ & {$[-0.02,0.01]$} & - & - \\
\hline Mean Coparenting Conflict & $1.43(0.04)^{*}$ & {$[1.36,1.51]$} & $1.37(0.03)^{*}$ & {$[1.31,1.43]$} \\
\hline$\Delta$ Coparenting Conflict & $-0.02(0.02)$ & {$[-0.06,0.01]$} & - & - \\
\hline
\end{tabular}

Note. ERC = Ethnoracial composition of dyad; MFS = Mother Family Support; FFS = Father Family

Support. Family support was grand-mean centered in each of the models. Mothers' and fathers' coparenting conflict were correlated in each of the models. Each model controlled for number of kids in the household. $\dagger p<.10 *$ indicates that the $95 \%$ Bayesian CI does not include zero. 


\section{Table 7}

Unstandardized Interaction Between Ethnoracial Composition and Family Support at T4

\begin{tabular}{|c|c|c|c|c|}
\hline \multirow[b]{2}{*}{ Model } & \multicolumn{2}{|c|}{ Model 1 (Original Model) } & \multicolumn{2}{|c|}{ Model 2 (Final Model) } \\
\hline & Coefficient $(S D)$ & $95 \% C I$ & Coefficient $(S D)$ & $95 \% C I$ \\
\hline \multicolumn{5}{|l|}{ Mothers } \\
\hline ERC $\rightarrow$ Conflict & $0.03(0.05)$ & {$[-0.07,0.13]$} & $0.08(0.04) \dagger$ & {$[-0.01,0.15]$} \\
\hline MFS $\rightarrow$ Conflict & $0.00(0.01)$ & {$[-0.02,0.02]$} & - & - \\
\hline FFS $\rightarrow$ Conflict & $-0.01(0.01)$ & {$[-0.03,0.02]$} & - & - \\
\hline ERC x MFS $\rightarrow$ Conflict & $-0.01(0.02)$ & {$[-0.05,0.02]$} & - & - \\
\hline ERC $x$ FFS $\rightarrow$ Conflict & $-0.01(0.02)$ & {$[-0.04,0.03]$} & - & - \\
\hline $\mathrm{ERC} \rightarrow \Delta$ Conflict & $-0.02(0.02)$ & {$[-0.05,0.02]$} & - & - \\
\hline MFS $\rightarrow \Delta$ Conflict & $0.002(0.003)$ & {$[-0.01,0.01]$} & - & - \\
\hline FFS $\rightarrow \Delta$ Conflict & $0.00(0.003)$ & {$[-0.01,0.01]$} & - & - \\
\hline ERC $x$ MFS $\rightarrow \Delta$ Conflict & $-0.003(0.01)$ & {$[-0.02,0.01]$} & - & - \\
\hline ERC $x$ FFS $\rightarrow \Delta$ Conflict & $0.004(0.01)$ & {$[-0.01,0.01]$} & - & - \\
\hline Mean Coparenting Conflict & $1.47(0.05)^{*}$ & {$[1.38,1.57]$} & $1.43(0.04)^{*}$ & {$[1.36,1.51]$} \\
\hline$\Delta$ Coparenting Conflict & $0.05(0.02)^{*}$ & {$[0.02,0.09]$} & - & - \\
\hline \multicolumn{5}{|l|}{ Fathers } \\
\hline ERC $\rightarrow$ Conflict & $0.06(0.06)$ & {$[-0.05,0.17]$} & $0.04(0.04)$ & {$[-0.03,0.13]$} \\
\hline FFS $\rightarrow$ Conflict & $-0.01(0.01)$ & {$[-0.04,0.02]$} & $-0.02(0.01)^{*}$ & {$[-0.03,-0.003]$} \\
\hline MFS $\rightarrow$ Conflict & $-0.01(0.01)$ & {$[-0.03,0.01]$} & $-0.01(0.01)$ & {$[-0.02,0.003]$} \\
\hline ERC $x$ FFS $\rightarrow$ Conflict & $-0.02(0.02)$ & {$[-0.06,0.03]$} & $-0.01(0.01)$ & {$[-0.04,0.01]$} \\
\hline ERC x MFS $\rightarrow$ Conflict & $0.02(0.02)$ & {$[-0.02,0.04]$} & $0.02(0.01) \dagger$ & {$[-0.002,0.04]$} \\
\hline $\mathrm{ERC} \rightarrow \Delta$ Conflict & $0.01(0.02)$ & {$[-0.03,0.05]$} & - & - \\
\hline FFS $\rightarrow \Delta$ Conflict & $0.004(0.01)$ & {$[-0.01,0.01]$} & - & - \\
\hline MFS $\rightarrow \Delta$ Conflict & $-0.003(0.004)$ & {$[-0.01,0.01]$} & - & - \\
\hline ERC $x$ FFS $\rightarrow \Delta$ Conflict & $0.001(0.01)$ & {$[-0.01,0.02]$} & - & - \\
\hline ERC x MFS $\rightarrow \Delta$ Conflict & $0.001(0.01)$ & {$[-0.01,0.01]$} & - & - \\
\hline Mean Coparenting Conflict & $1.37(0.05)^{*}$ & {$[1.27,1.47]$} & $1.45(0.03)^{*}$ & {$[1.38,1.50]$} \\
\hline$\Delta$ Coparenting Conflict & $-0.02(0.02)$ & {$[-0.06,0.02]$} & - & - \\
\hline
\end{tabular}

Note. ERC = Ethnoracial composition of dyad; MFS = Mother Family Support; FFS = Father Family Support. Family support was grand-mean centered in each of the models. Mothers' and fathers' coparenting conflict were correlated in each of the models. Each model controlled for number of kids in the household. $\dagger p<.10 *$ indicates that the $95 \%$ Bayesian CI does not include zero. 


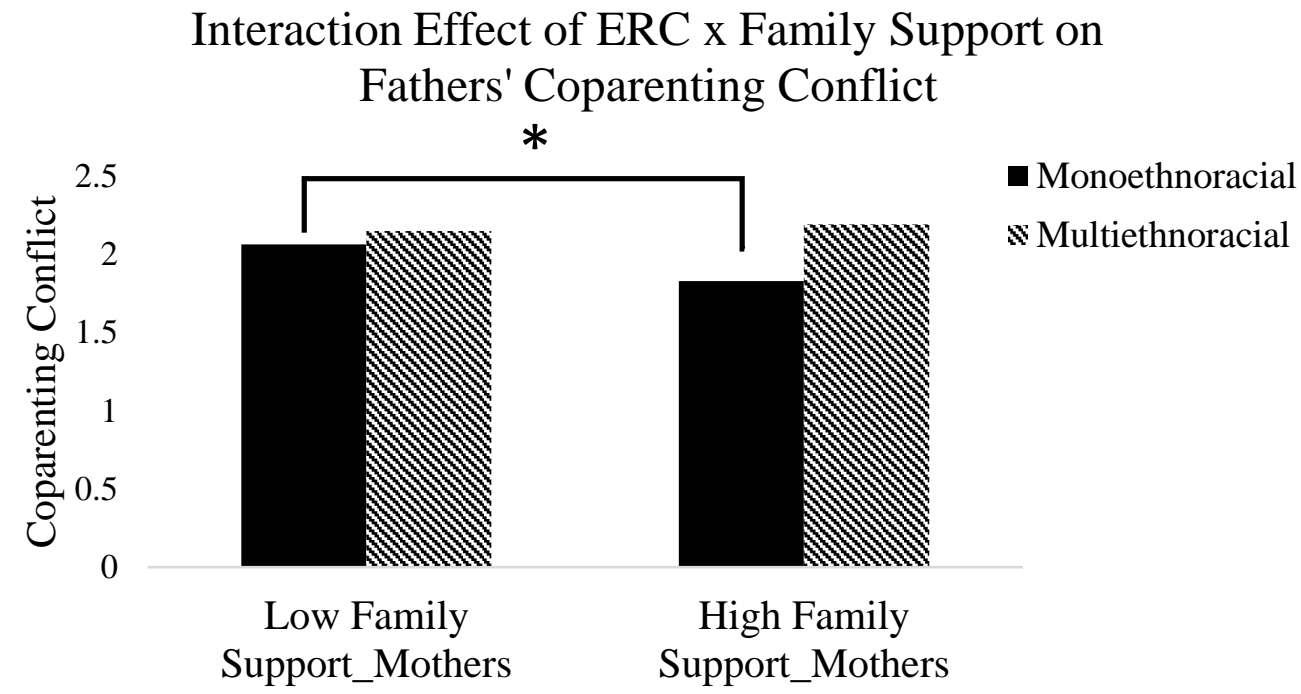

Figure 4. The figure illustrates the interaction effect of family support and family ethnoracial composition on coparenting conflict at $\mathrm{T} 1$ for fathers.

\section{Mediation Models}

Finally, to test the last research question of whether social support mediated the relationship between family ethnic composition and co-parenting conflict over the transition to parenthood a multilevel structural equation modeling was used (MLSEM; Preacher, Zyphur, Zhang, 2010).

Contrary to what was expected, the predicted model did not result in any significant indirect paths. Ethnoracial composition was significantly negatively associated with maternal family support $(B=-1.12,95 \% C I=[-2.04,-0.21], p=.02)$, but not to coparenting conflict $(B=0.04,95 \% C I=[-0.07,0.13], p=.44)$, when controlling for partner effects and depression. Mothers in MER dyads experienced 1.12 units less family support than mothers in MoER dyads. However, mother's family support was not related to coparenting conflict $(B=-0.01,95 \% C I=[-0.02,0.01], p=.50)$. For fathers, ethnoracial composition was not related to their family support $(B=-0.77,95 \% C I=[-$ $1.94,0.36], p=.18)$ or coparenting conflict $(B=0.05,95 \% C I=[-0.07,0.15], p=.40)$. 
Fathers' family support was also not related to coparenting conflict $(B=-0.01,95 \% C I=$ $[-0.03,0.004], p=0.13)$. Partner effects were estimated in the predicted mediation model, but no partner effects were significant. See Model 1 in Table 8 for unstandardized coefficients from this model.

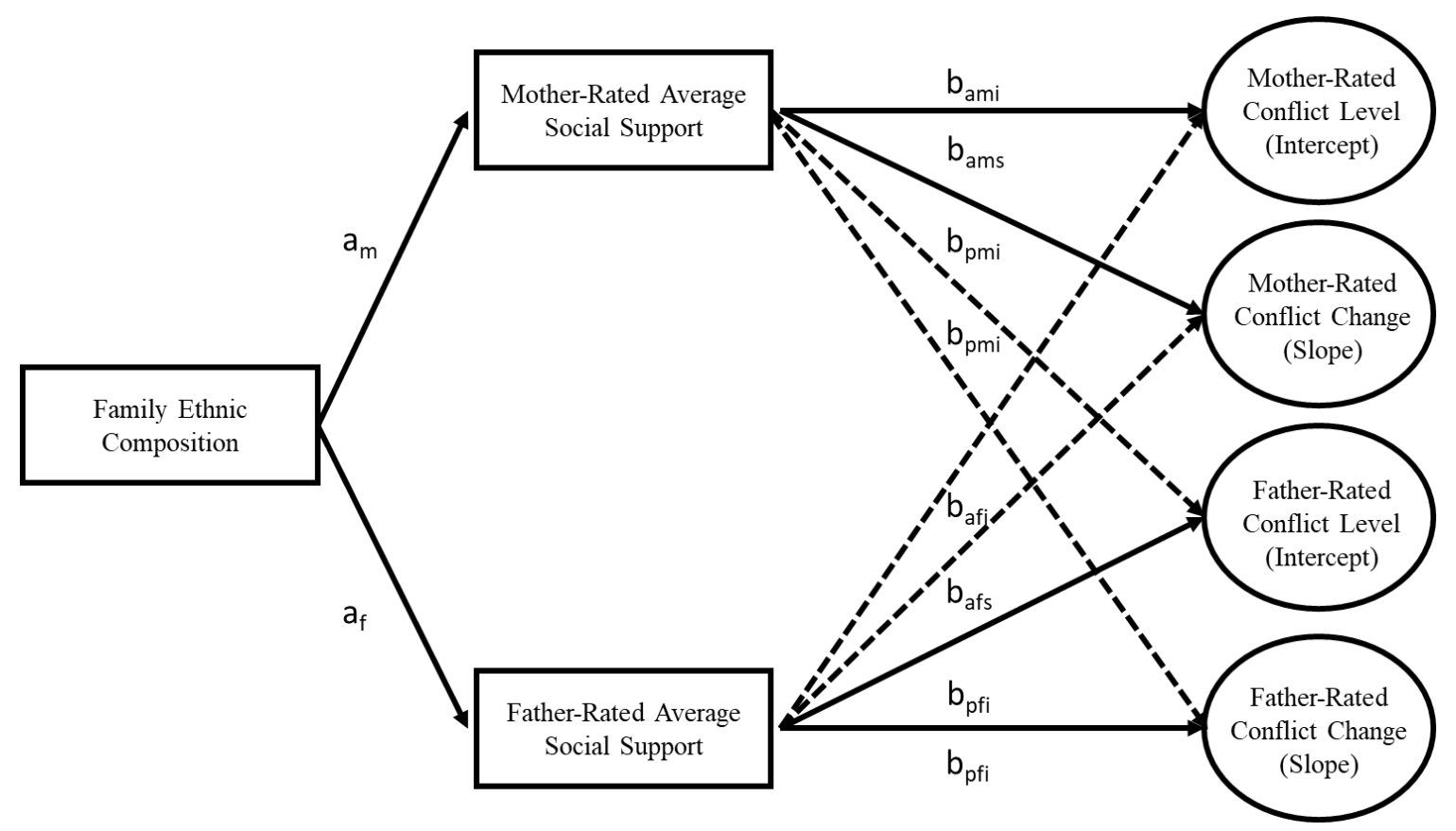

Figure 6. The hypothesized mediation model in which family ethnoracial composition predicts the level and change in coparenting conflict through perceived differences in family support for mothers and fathers. For simplicity, only the "a" and "b" pathways are depicted which are used to test the indirect effects. The model does, however, include the direct effects of ethnoracial composition on coparenting conflict for mothers and fathers ("c" path) which are not depicted.

Similar to the moderation model, the predicted mediation model may have estimation problems since the model is complex and the groups being compared are small (Goodboy \& Kline, 2017). Thus, to make the model more parsimonious and to correct for potential estimation problems the model was simplified with a posteriori trimming of pathways that were not meaningfully significant to the model. In the trimmed model, all the associations for mothers were retained. However, for fathers new associations arose. The trimmed model revealed a trend-level indirect effect of ethnoracial composition on 
coparenting conflict through family support $(B=0.02,95 \% C I=[-0.01,0.06], p=.09)$; that is, fathers in MER dyads had less family support than MoER dyads $(B=-0.94,95 \%$ $C I=[-2.09,0.12], p=.09)$ which in turn was associated with greater coparenting conflict one-year postpartum $(B=-0.02,95 \% C I=[-0.03,-0.01], p<.001)$. Partner effects were estimated in the trimmed mediation model, but no partner effects were significant. See Model 2 in Table 8 for unstandardized coefficients from this model.

Overall, the results suggest that mothers in MER dyads experience greater levels of coparenting conflict, but their coparenting conflict increases less across early parenthood compared to mothers in MoER dyads. Meanwhile, fathers do not differ in their levels or change in coparenting conflict by ethnoracial composition. In addition, the results found that mothers in MER dyads have less family support than mothers in MoER dyads. However, this difference in family support is not related to their coparenting conflict. Moreover, family support does not interact with ethnoracial composition to predict coparenting conflict for mothers. When controlling for the effects of mothers' and fathers' family support, mothers' family support interacted with the ethnoracial composition (ERC) of the dyad, such that fathers in MoER dyads have less coparenting conflict when mothers' family support is high, but not for fathers in MER dyads. Last, an indirect effect was found in which fathers in MER dyads had less family support than MoER dyads which predicted greater coparenting conflict one-year postpartum. 


\section{Table 8}

Unstandardized Associations Among Ethnoracial Composition, Family Support, and Coparenting Conflict

\begin{tabular}{|c|c|c|c|c|}
\hline \multirow[b]{2}{*}{ Model } & \multicolumn{2}{|c|}{ Model 1 (Original Model) } & \multicolumn{2}{|c|}{ Model 2 (Final Model) } \\
\hline & Coefficient $(S D)$ & $95 \% C I$ & Coefficient $(S D)$ & $95 \% C I$ \\
\hline \multicolumn{5}{|l|}{ Mothers } \\
\hline ERC $\rightarrow$ Conflict (c' path) & $0.04(0.05)$ & {$[-0.07,0.13]$} & $0.05(0.04)$ & {$[-0.04,0.14]$} \\
\hline MFS $\rightarrow$ Conflict ( $b_{a}$ path) & $-0.01(0.01)$ & {$[-0.02,0.01]$} & $-0.01(0.01)$ & {$[-0.02,0.003]$} \\
\hline FFS $\rightarrow$ Conflict (b $b_{p}$ path) & $-0.01(0.01)$ & {$[-0.03,0.01]$} & $-0.01(0.01) \dagger$ & {$[-0.03,0.00]$} \\
\hline ERC $\rightarrow \Delta$ Conflict (c' path) & $-0.01(0.02)$ & {$[-0.05,0.03]$} & - & - \\
\hline MFS $\rightarrow \Delta$ Conflict ( $b_{a}$ path) & $0.001(0.003)$ & {$[-0.01,0.01]$} & - & - \\
\hline FFS $\rightarrow \Delta$ Conflict ( $b_{p}$ path) & $0.00(0.003)$ & {$[-0.01,0.01]$} & - & - \\
\hline ERC $\rightarrow$ MFS (a path) & $-1.12(0.45)^{*}$ & {$[-2.04,-0.21]$} & $-1.17(0.46)^{*}$ & {$[-2.00,-0.27]$} \\
\hline Mean Family Support & $12.06(0.60)^{*}$ & {$[10.95,13.24]$} & $12.12(0.63)^{*}$ & {$[10.82,13.26]$} \\
\hline Mean Coparenting Conflict & $1.63(0.15)$ & {$[-0.07,0.14]$} & $1.66(0.11)^{*}$ & {$[1.42,1.86]$} \\
\hline$\Delta$ Coparenting Conflict & $0.04(0.05)$ & {$[-0.07,0.14]$} & - & - \\
\hline \multicolumn{5}{|l|}{ Fathers } \\
\hline ERC $\rightarrow$ Conflict (c' path) & $0.05(0.06)$ & {$[-0.07,0.15]$} & $0.03(0.04)$ & {$[-0.04,0.11]$} \\
\hline MFS $\rightarrow$ Conflict ( $b_{a}$ path) & $-0.01(0.01)$ & {$[-0.03,0.01]$} & $-0.01(0.01)$ & {$[-0.02,0.01]$} \\
\hline FFS $\rightarrow$ Conflict (b $b_{p}$ path) & $-0.01(0.01)$ & {$[-0.03,0.004]$} & $-0.02(0.01)^{*}$ & {$[-0.03,-0.01]$} \\
\hline ERC $\rightarrow \Delta$ Conflict (c' path) & $0.02(0.02)$ & {$[-0.03,0.05]$} & - & - \\
\hline MFS $\rightarrow \Delta$ Conflict ( $b_{a}$ path) & $-0.003(0.003)$ & {$[-0.01,0.004]$} & - & - \\
\hline FFS $\rightarrow \Delta$ Conflict ( $b_{p}$ path) & $0.01(0.004)$ & {$[-0.002,0.01]$} & - & - \\
\hline ERC $\rightarrow$ FFS (a path) & $-0.77(0.58)$ & {$[-1.94,0.36]$} & $-0.94(0.58) \dagger$ & {$[-2.09,0.12]$} \\
\hline Mean Family Support & $11.20(0.59)^{*}$ & {$[10.04,12.39]$} & $11.30(0.64)^{*}$ & {$[10.16,12.63]$} \\
\hline Mean Coparenting Conflict & $1.62(0.13)^{*}$ & {$[1.39,1.88]$} & $1.72(0.10)^{*}$ & {$[1.54,1.92]$} \\
\hline$\Delta$ Coparenting Conflict & $-0.05(0.05)$ & {$[-0.14,0.06]$} & - & - \\
\hline
\end{tabular}

Note. ERC = Ethnoracial composition of dyad; MFS = Mother Family Support; FFS = Father Family Support. $\mathrm{c}^{\prime}=$ the direct effect of the predictor (ERC) on outcome (Coparenting Conflict) controlling for the actor and partner mediators (MFS and FFS); $b=$ the effect of the mediators (MFS and FFS) on the outcome (Coparenting Conflict), controlling for the predictor variable (ERC); $a=$ the effect of the predictor (ERC) on the mediators (MFS and FFS), controlling for the outcome variable (Coparenting Conflict). Mothers' and fathers' coparenting conflict and family support were correlated in each of the models. Each model controlled for depression. $\dagger p<.10 *$ indicates that the $95 \%$ Bayesian CI does not include zero.

\section{Exploratory Analyses}

Previous literature has suggested that White mothers in relationships with fathers of color are likely to perceive the least support from their families when compared to 
MER dyads with two parents of color and MoER families (Bratter \& Whitehead, 2019).

Although the current sample was too small to detect robust differences, variability within groups were still of interest. Therefore, exploratory analyses were conducted to examine possible trends in the data for different types of MER families.

Looking first at social support across dyads, analyses revealed a trend-level difference in family support, such that White Mothers in MoER dyads $(M=3.44)$ reported higher family support compared to White mothers in MER dyads $(M=3.13)$; $F(4,136)=2.17, p=.09$. Meanwhile, fathers of color partnered with White mothers $(M=$ 3.56) perceived more family support than fathers in any other MER dyad types (WPOC $M=2.89 ; \mathrm{W}-\mathrm{POC} ; F(4,77)=2.83, p=.07)(\mathrm{POC}-\mathrm{POC} M=2.98 ; F(4,77)=$ 2.83, $p=.05)$ (see Tables 8 and 9).

In regards to coparenting, it was also found that after mothers returned to work fathers of color/mother of color MER dyads $(M=2.76)$ had more coparenting conflict than fathers of color/White mother MER dyads $(M=1.90)(F(4,94)=2.48, p=.04)$ and fathers of color in MoER dyads $(M=2.13)(F(4,94)=2.48, p=.10)$. No other differences in family support and coparenting conflict were found between different family types likely due to the small sample.

In addition, changes in coparenting conflict over time were examined. Fathers' coparenting conflict increased more over the transition to parenthood for White mother/father of color dyads compared to mother of color/White father dyads $(B=0.11$, $95 \% C I=[0.01,0.21], p=.04)$. In examining descriptive data, both partners in White mother/father of color dyads report low conflict immediately after their child is born and 
steadily perceive more conflict as time progresses while parents in mother of color/White father dyads report high conflict immediately after their child is born and steadily 


\section{Table 8}

Descriptive Statistics for Family Support and Coparenting Conflict with Expanded Ethnoracial Composition Categories

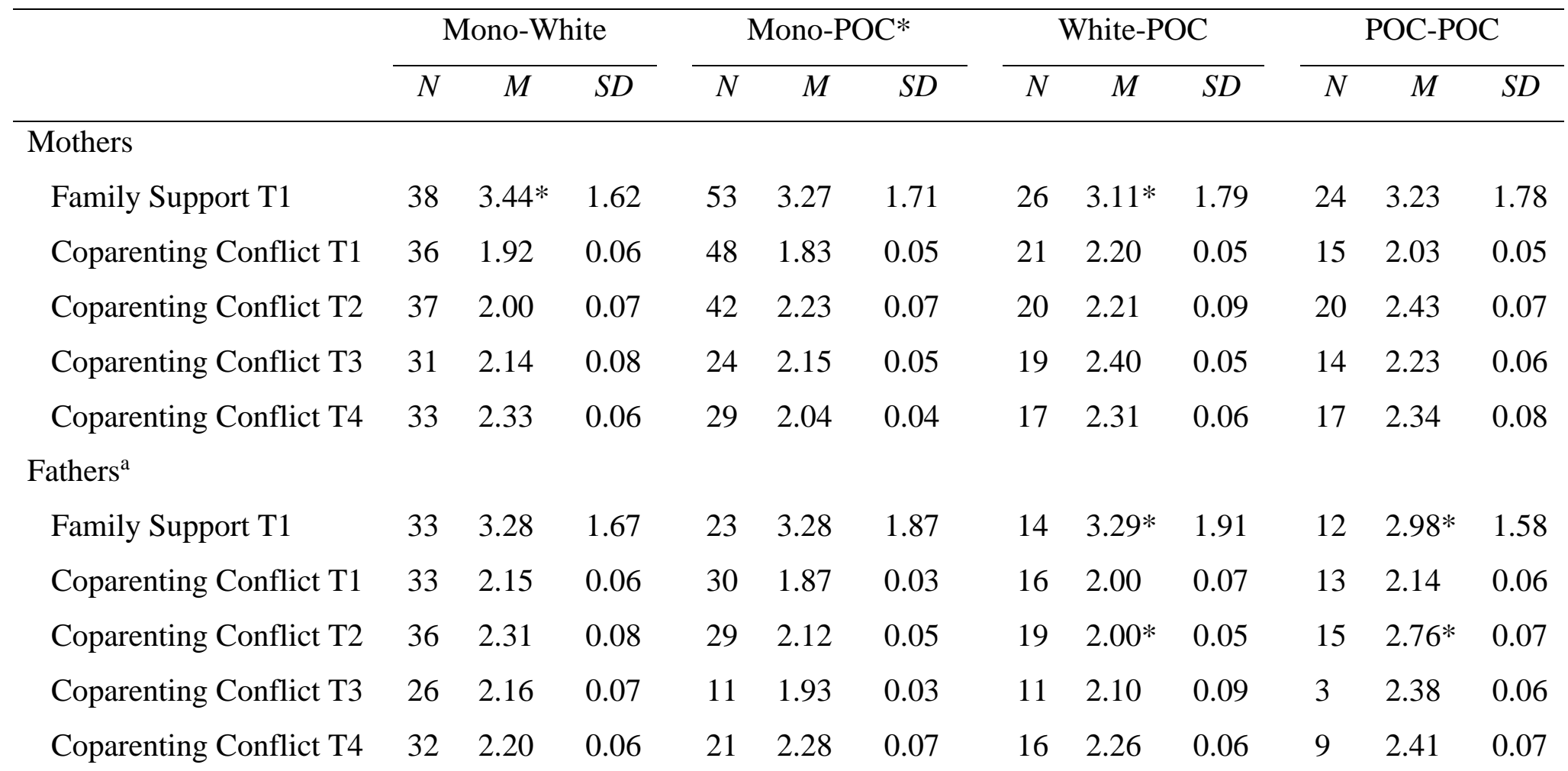

Note. ${ }^{*} \mathrm{POC}=$ person of color ${ }^{\mathrm{a}}$ Fathers have a lower sample size than mothers because they were less likely to participate in the study or complete all the questionnaires associated with the study at each time point. 
perceive less conflict as time progresses. In contrast, MER dyads with two parents of color have more variable perceptions of coparenting conflict in which their conflict initially increases from when the baby is born to mother's return to work, then decreases and increases again by the end of the first year of parenthood. These findings suggest there might be different processes happening within different MER family types which are important to study. It also suggests that gender and ethnicity/race may interact and be important to examine simultaneously in studying family processes in different types of ethnoracial parent dyads (see Table 9).

\section{Table 9}

Descriptive Statistics for Family Support and Coparenting Conflict with Expanded Ethnoracial Composition Categories by Gender

\begin{tabular}{|c|c|c|c|c|c|c|}
\hline & \multicolumn{3}{|c|}{ White-POC* } & \multicolumn{3}{|c|}{ POC-White } \\
\hline & $N$ & $M$ & $S D$ & $N$ & $M$ & $S D$ \\
\hline \multicolumn{7}{|l|}{ Mothers } \\
\hline Family Support T1 & 20 & 3.13 & 1.82 & 6 & 3.07 & 1.72 \\
\hline Coparenting Conflict T1 & 15 & 2.10 & 0.04 & 6 & 2.47 & 0.08 \\
\hline Coparenting Conflict T2 & 14 & 2.18 & 0.10 & 6 & 2.29 & 0.10 \\
\hline Coparenting Conflict T3 & 14 & 2.43 & 0.04 & 5 & 2.31 & 0.11 \\
\hline Coparenting Conflict T4 & 14 & 2.40 & 0.07 & 3 & 1.91 & 0.01 \\
\hline \multicolumn{7}{|l|}{ Fathers } \\
\hline Family Support T1 & 8 & $3.56^{*}$ & 1.70 & 6 & $2.89^{*}$ & 1.79 \\
\hline Coparenting Conflict T1 & 11 & 1.88 & 0.05 & 5 & 2.27 & 0.10 \\
\hline Coparenting Conflict T2 & 13 & $1.89^{*}$ & 0.03 & 6 & $2.24 *$ & 0.11 \\
\hline Coparenting Conflict T3 & 7 & 2.10 & 0.05 & 4 & 2.09 & 0.22 \\
\hline Coparenting Conflict T4 & 13 & 2.37 & 0.05 & 3 & 1.79 & 0.08 \\
\hline
\end{tabular}




\section{CHAPTER IV}

\section{DISCUSSION}

The current study examined differences in coparenting conflict in a sample of multiethnoracial (MER; parents from different racial or ethnic backgrounds) and monoethnoracial (MoER; parents from the same racial or ethnic background) parents experiencing the transition to parenthood. These relationships were examined in a unique sample of low-income, working parents experiencing the transition to parenthood and return to paid work soon after the child's birth. The role of family support was also investigated as a possible moderator and/or mediator of the relationship between coparenting conflict and family ethnoracial composition.

\section{Coparenting Conflict}

To our knowledge, this study was the first quantitative studies of its kind to investigate coparenting conflict during the transition to parenthood for MER families. Confirming findings from previous qualitative studies on multiethnoracial (MER) families (Bratter \& King, 2008; Crippen \& Brew, 2013; Kang Fu \& Wolfinger, 2011; Sharaievska, Kim, \& Stodolska, 2013), mothers in MER dyads reported more coparenting conflict than mothers in MoER dyads, both right after the birth and one-year postpartum. In contrast, fathers' reports of coparenting conflict did not differ by the ethnoracial composition of the dyad. One reason fathers may not have differences in coparenting conflict based on ethnoracial composition is that coparenting conflict is not a concern yet for fathers. Differences in coparenting conflict for fathers have primarily been conducted later in parenthood, the earliest being around two-years postpartum (Bronte-Tinkew, Scott, Horowitz, \& Lilja, 2009). Not much is known about coparenting 
conflict in infancy for fathers, so it may be that fathers' coparenting conflict does not increase until later in childhood (e.g., two years postpartum). So, studying coparenting conflict within the first year of infancy may not capture the disruptions in coparenting that happen with fathers. Future studies could benefit from studying fathers' coparenting conflict in MER families during toddlerhood when it may be more likely to rise for fathers.

It was also hypothesized that parents in MER dyads would report steeper increases in conflict compared to MoER dyads, however, this hypothesis was not supported. Instead, it was found that mothers in MER dyads had less steep of an increase in coparenting conflict compared to MoER dyads, the opposite of what was expected. Given that mothers in MER dyads have higher conflict at both the beginning and end of the study, one possible explanation is that mothers in MER dyads start high on coparenting conflict and do not have the same growth potential as mothers in MoER dyads who start with lower coparenting conflict at one-month postpartum. These findings suggest that MER couples have higher conflict very soon after the birth compared to MoER couples, raising questions about whether their couple conflict may have already been higher pre-birth than MoER couples. MER couples may head into the rocky transition to parenthood already in an unsteady position in their relationship.

Fathers' change in coparenting conflict did not differ for men in MER or MoER couples. Exploratory analyses suggested, however, that coparental conflict may change in different ways for different types of MER families. Specifically, White mother/father of color MER dyads and mother of color/White father MER dyads changed in the opposite directions on fathers' coparenting conflict. Fathers in White mother/father of color dyads 
initially start with low levels of coparenting conflict which increased over the first year of parenthood, while fathers in mother of color/White father dyads initially started with high levels which decreased over the first year of parenthood. These signals in our data suggest that the change in coparenting conflict for MER families may not be accurately captured by grouping these different types of families together who are meaningfully different. Why might these differences occur? It may be that early in parenthood, maternal characteristics, support, and stressors are most salient to the family's functioning (Van Egeren, 2003). However, as fathers' engagement becomes more integral over time, this may be when fathers experience greater conflict over parenting beliefs. For instance, Roy et al. (2019) specifically describe instances of conflict between white mothers and fathers of color over the issue of child discipline. It may be that the primary topics that parents have conflict over in White mother/father of color dyads such as disciplining children and spoiling do not emerge until later in infancy. Meanwhile, mother of color/white father dyads may experience high conflict earlier in infancy due to violated expectations regarding new tasks of childcare. Bolzendahl and Gubernskaya (2016) found that gender and race interacted to influence the amount of housework completed by women, such that when White women were partnered with Black men they did less housework then if partnered with White or Latino men. This same phenomenon may be at play, wherein women of color are completing more childcare-related tasks than expected had they been parenting with someone from the same racial/ethnic background. Violated expectations is understudied in MER families and may help to explain high coparental conflict for certain compositions of families. Differences in the change in 
coparenting conflict between MER and MoER dyads may also be better captured by comparing distinct groups within the two broad ethnoracial categorizations.

\section{Coparenting Conflict and Family Support}

Two possible methods by which social support could function for multiethnoracial (MER) and monoethnoracial (MoER) parents were examined. First, social support could buffer the relationship between ethnoracial composition and coparenting conflict. Specifically, it was hypothesized that under conditions of high family support coparenting conflict would be low for MER dyads, whereas under conditions of low family support coparenting conflict would be especially high since they are the most isolated from social support networks (Ngai \& Ngu, 2014). Contrary to what was expected, ethnoracial composition and family support did not interact to predict coparenting conflict for mothers. However, a cross-over effect was found such that mothers' high family support buffered the relationship between ethnoracial composition and coparenting conflict for fathers in MoER couples. Meanwhile, fathers in MER dyads had equivalent levels of coparenting conflict regardless of mothers' family support. It may be that family support is not enough to buffer fathers' coparenting conflict in MER dyads when they are experiencing repeated exposure to prejudice and discrimination (Brummett \& Steuber, 2014; Cheng \& Powell, 2007). Individual partners within MER dyads may also have different experiences of discrimination and privilege which may be a source of conflict and be an explanatory factor for differences in conflict between MER and MoER parent dyads (Kendall, 2012; Roy et al., 2019; Schmitt \& Branscombe, 2002). That is, if fathers experience prejudice or discrimination outside the home, they may be more stressed and vulnerable to conflict with their partner. In addition, when partners in 
MER dyads experience prejudice or discrimination, some have described their partner as not being supportive because they have not experienced racial discrimination specifically, especially for White/Person of Color dyads (Roy \& Rollins, 2019). Therefore, discrimination and prejudice may be an important factor to study when understanding MER family dynamics and outcomes.

Second, it was hypothesized that being in a MER dyad would predict less family support and, in turn, predict greater coparental conflict. Although being in a MER dyad was related to less family support for mothers, family support was not subsequently related to coparental conflict, contrary to what was expected. One possible explanation for the lack of results may have to do with our measure of family support. In the current study, we examined emotional support which has previously been shown to be related to coparenting conflict (Bost et al., 2002). However, it may be the case for the parents in this study, who were all low-income families and all returning to work soon after birth, that more instrumental types of support, like childcare or financial help from family, would be more critical than emotional support (Sousa \& Rodrigueus, 2009). Future studies might benefit by looking at the links between both instrumental and emotional family supports and coparenting conflict for families in low-income communities.

Similar to Bratter and Whitehead (2019), the current study found that mothers in MER dyads experienced less family support compared to mothers in MoER dyads. Research shows that greater family support, especially during the transition to parenthood, is protective against stress and conflict, as well as improves parenting sensitivity/effectiveness and improves health outcomes (Bost et al., 2002; Collins et al., 1993; Graignic-Philippe, Dayan, Chokron, Jacquet, \& Tordjman, 2014; Ngai \& Ngu, 
2014; Wandersman, Wandersman, \& Kahn, 1980). Thus, mothers in MER families with less support face greater susceptibility to stress and higher risk to poor familial, developmental and health outcomes. One potential reason mothers in MER dyads may experience lower family support is that their extended kin (e.g., grandparents, aunts, cousins) may disapprove of their relationship by nature of being with a partner from a different ethnoracial background (Bell \& Hastings, 2015). MER dyads are more likely to face greater disapproval and stigma about their relationships, due to a legacy of racism (Brummett \& Steuber, 2014; Cheng \& Powell, 2007). Future studies should consider investigating the dyads experience of prejudice and discrimination and other factors that might illuminate why MER families are experiencing less family support than MoER families.

Our hypothesis of a mediated pathway linking ethnoracial match to coparenting conflict via less family support received partial support. There was a trend in which being in a MER parent dyad predicted less family support for fathers which in turn led to greater coparenting conflict. This difference in family support between MER and MoER dyads has been documented for mothers by Bratter \& Whitehead (2019). This study extends that research by now finding this process with MER fathers. This study also extends the research from Bost and colleagues (2002) which found a link between coparenting conflict and family support. An important next step would be to examine possible discrepancies between cultural values about family involvement and the actual family support received which could influence coparenting conflict more for some compositions of families over others. For example, MER families with one Latinx partner 
might experience more conflict if they experience less family support than they would have otherwise received had they been in an MoER family structure.

Differences in family support based on ethnoracial composition for fathers may be washed out by merging different types of MER families in one broad category. Unfortunately, group sizes within the sample of MER dyads were too small to examine beyond the descriptive level. Descriptively, at least, fathers in mother of color/White father dyads experienced the least amount of family support of any composition whereas fathers of color coupled with White mothers have the most support compared to any composition. From a social exchange perspective, this trend may be related to status (Kalmjin, 1993; Hou \& Myles, 2013). It is postulated that men of color could experience positive outcomes in MER relationships with White women since they are increasing their access to social resources or capital (Cheng \& Powell, 2007). Fathers in dyads with two people of color (POC-POC) also experienced lower family support than the other dyad types which is meaningful since the literature would suggest that families of color (e.g., Latinx, Asian) tend to value, expect, and receive higher levels of family support than White families (Haxton \& Harknett, 2009; Hogan, Eggebeen, \& Clogg, 1993; Kim \& McKenry, 1998; Taylor, Chatters, Woodward, \& Brown, 2013). This suggests that the fathers in POC-POC dyads, in the current sample, might be particularly vulnerable if they had expected to receive family support when starting a family and that expectation was not met. Future directions of this research would be to see how fathers from different ethnoracial dyad types value familial involvement, how much support they expect to receive from their and their coparent's family, and the differential effects of overall family support compared to their own family's support or their partner's family support. 


\section{Family Ethnoracial Composition}

The present study found that all MER families are not the same and, consistent with previous literature, the composition of the dyads may have implications for coparenting conflict (Roy \& Rollins, 2019). One explanation for why they differ may be due to the fact that partners' interactions may be differentially shaped by their experiences of privilege or discrimination (Kendall, 2012; Roy et al., 2019; Schmitt \& Branscombe, 2002). Future research should explore how racism, experienced by individuals and the couple affect conflict and stress.

\section{Limitations}

The primary limitation of the current study was that the group sizes of multiethnoracial (MER) families were too small to examine within-group differences more systematically. Another barrier was related to the measurement of family support. Our measure of family support did not have information on parents' ideas regarding what level and kind of family involvement or support they expected once their child was born, the different kinds of supports they receive from their family, and what their family support was like prior to entering in their relationships. Knowing parents' values regarding what kinds of supports they expected to receive from their family may be important to differentiate which dyadic compositions might be more affected by the lack of family support. For example, Latinx and Asian families are more likely to rely on familial support compared to European Americans and African Americans (Haxton \& Harknett, 2009; Hogan, Eggebeen, \& Clogg, 1993; Kim \& McKenry, 1998; Taylor, Chatters, Woodward, \& Brown, 2013). Therefore, a dyad with a Latinx or Asian American partner might experience more conflict if there is a discrepancy between what 
they expected to receive based on their familism values and what level of support they have received from their extended family.

Another issue that may have affected the results is that changes in family support are likely to have happened much earlier when couples first entered into the relationship. In short, the MER couples in this study may have experienced their decrease in family support when they first became a couple. Finally, the current study did not tap into the salience of racial or ethnic identity for parents. The importance of one's racial and ethnic identity to a sense self may also be an important factor to investigate; if a partners does not strongly identify with their racial or ethnic heritage there may be less conflict emerging between partners related to cultural differences.

\section{Conclusion}

The present study found that mothers in multiethnoracial (MER) dyads experience greater coparenting conflict and lower familial support than their monoethnoracial (MoER) counterparts during the transition to parenthood. In addition, when mothers' family support was high, fathers in MoER dyads reported less coparenting conflict, while fathers in MER dyads had the same level of coparenting conflict regardless of mothers' family support. Last, it was found that fathers in MER dyads experienced less family support than MoER dyads which in turn led to greater coparenting conflict for fathers. The present study was one of the first to quantitatively examine coparenting conflict and confirm theories suggesting that conflict may be one possible explanatory factor for instability in MER couples. In addition, the current study extends the study of MER families to the transition to parenthood which is a critical transitionary period for parents and developmental period for children. With higher conflict and lower family support, 
MER families are at greater risk for stress and, subsequently, poor familial, developmental, and health outcomes. Currently, there is a lack of attention given to research on the unique experience of MER families. It is imperative to understand the unique family processes for MER families experiencing unique stressors in addition to the normative transitionary challenges all couples face, that place them at risk for relationship dissolution and poorer well-being. 


\section{BIBLIOGRAPHY}

Ahrons, C. R. (1981). The continuing coparental relationship between divorced spouses. American Journal of Orthopsychiatry, 51(3), 415-428. doi:10.1037/t01210-000

American Psychological Association (2017) Multicultural Guidelines: An Ecological Approach to Context, Identity, and Intersectionality. Retrieved from: http://www.apa.org/about/policy/multicultural-guidelines.pdf

Armstrong, M. I., Birnie-Lefcovitch, S., \& Ungar, M. T. (2005). Pathways between social support, family well being, quality of parenting, and child resilience: What we know. Journal of Child and Family Studies, 14(2), 269-281. doi:10.1007/s10826005-5054-4

Bartholomew, M. K., Schoppe-Sullivan, S. J., Glassman, M., Kamp Dush, C. M., \& Sullivan, J. M. (2012). New parents' Facebook use at the transition to parenthood. Family Relations, 61(3), 455-469. doi:10.1111/j.17413729.2012.00708.x

Bell, G. C., \& Hastings, S. O. (2015). Exploring parental approval and disapproval for Black and White interracial couples. Journal of Social Issues, 71(4), 755-771. doi:10.1111/josi.12147

Belsky, J., \& Pluess, M. (2009). Beyond diathesis stress: differential susceptibility to environmental influences. Psychological bulletin, 135(6), 885-908. doi:10.1037/a0017376 
Belsky, J., Spanier, G. B., \& Rovine, M. (1983). Stability and change in marriage across the transition to parenthood. Journal of Marriage and the Family, 567-577. doi:10.2307/351661

Berry, J. W. (1997). Immigration, acculturation, and adaptation. Applied Psychology, 46(1), 5-34. doi:10.1111/j.1464-0597.1997.tb01087.x

Bhugun, D. (2017). Intercultural parenting in Australia: Managing cultural differences. The Family Journal: Counseling and Therapy for Couples and Families, 25(2), 187-195. doi:10.1177/1066480717697688

Bialik, K. (2017). Key facts about race and marriage, 50 years after Loving v. Virginia. Fact Tank-Our Lives in Numbers, Pew Research Center. Retrieved from http://www.pewresearch.org/fact-tank/2017/06/12/key-facts-about-race-andmarriage-50-years-after-loving-v-virginia/

Bianchi, S. M., Sayer, L. C., Milkie, M. A., \& Robinson, J. P. (2012). Housework: Who did, does or will do it, and how much does it matter? Social Forces, 91(1), 55-63. doi:10.1093/sf/sos 120

Bobo, L., \& Zubrinsky, C. L. (1996). Attitudes on residential integration: Perceived status differences, mere in-group preference, or racial prejudice? Social Forces. doi:10.1093/sf/74.3.883

Bohannan, P. (2010). How culture works. New York, NY: Simon and Schuster.

Bolzendahl, C., \& Gubernskaya, Z. (2016). Racial and ethnic homogamy and gendered time on core housework. Socius, 2, 1-15. doi:10.1177/2378023116676277

Bost, K. K., Cox, M. J., Burchinal, M. R., \& Payne, C. (2002). Structural and supportive changes in couples' family and friendship networks across the transition to 
parenthood. Journal of Marriage and Family, 64(2), 517-531. doi:10.1111/j.17413737.2002.00517.x

Boustan, L. P. (2013). Racial residential segregation in American cities. In The Oxford handbook of urban economics and planning. doi:10.1093/oxfordhb/9780195380620.013.0015

Bratter, J. L., \& Eschbach, K. (2006). "What about the couple?” Interracial marriage and psychological distress. Social Science Research, 35(4), 1025-1047. doi:10.1016/j.ssresearch.2005.09.001

Bratter, J. L., \& King, R. B. (2008). “But will it last?”: Marital instability among interracial and same-race couples. Family Relations, 57(2), 160-171. doi:10.1111/j.1741-3729.2008.00491.x

Bratter, J. L., \& Whitehead, E. M. (2018). Ties that bind? Comparing kin support availability for mothers of mixed-race and monoracial infants. Journal of Marriage and Family, 80(4), 951-962. doi:10.1111/jomf.12485

Bronte-Tinkew, J., Scott, M. E., Horowitz, A., \& Lilja, E. (2009). Pregnancy intentions during the transition to parenthood and links to coparenting for first-time fathers of infants. Parenting: Science and Practice, 9(1-2), 1-35. doi:10.1080/15295190802656729

Brummett, E. A., \& Steuber, K. R. (2014). To reveal or conceal?: Privacy management processes among interracial romantic partners. Western Journal of Communication, 79(1), 22-44. doi: 10.1080/10570314.2014.943417

Buitelaar, J. K., Huizink, A. C., Mulder, E. J., de Medina, P. G. R., \& Visser, G. H. (2003). Prenatal stress and cognitive development and temperament in 
infants. Neurobiology of Aging, 24, S53-S60. doi:10.1016/S0197-4580(03)000502

Burchinal, M. R., Follmer, A., \& Bryant, D. M. (1996). The relations of maternal social support and family structure with maternal responsiveness and child outcomes among African American families. Developmental Psychology, 32(6), 10731083. doi:10.1037/0012-1649.32.6.1073

Burton, L. M., Bonilla-Silva, E., Ray, V., Buckelew, R., \& Hordge Freeman, E. (2010). Critical race theories, colorism, and the decade's research on families of color. Journal of Marriage and Family, 72(3), 440-459. doi:10.1111/j.17413737.2010.00712.x

Bustamante, R. M., Nelson, J. A., Henriksen Jr, R. C., \& Monakes, S. (2011). Intercultural couples: Coping with culture-related stressors. The Family Journal, 19(2), 154-164. doi:10.1177/1066480711399723

Cheng, S., \& Powell, B. (2007). Under and beyond constraints: Resource allocation to young children from biracial families. American Journal of Sociology, 112(4), 1044-1094. doi: 10.1086/508793

Chong, A., \& Mickelson, K. D. (2016). Perceived fairness and relationship satisfaction during the transition to parenthood: The mediating role of spousal support. Journal of Family Issues, 37(1), 3-28. doi:10.1177/0192513X13516764

Chun, K. M., \& Akutsu, P. D. (2003). Acculturation among ethnic minority families. In K. M. Chun, P. Balls Organista, \& G. Marín (Eds.), Acculturation: Advances in theory, measurement, and applied research (pp. 95-119). Washington, DC, US: American Psychological Association. 
Collins, N. L., Dunkel-Schetter, C., Lobel, M., \& Scrimshaw, S. C. (1993). Social support in pregnancy: Psychosocial correlates of birth outcomes and postpartum depression. Journal of Personality and Social Psychology, 65(6), 1243-1258. doi:10.1037/0022-3514.65.6.1243

Cook, W. L., \& Kenny, D. A. (2005). The actor-partner interdependence model: A model of bidirectional effects in developmental studies. International Journal of Behavioral Development, 29(2), 101-109. doi:10.1080/01650250444000405

Crippen, C., \& Brew, L. (2007). Intercultural parenting and the transcultural family: A literature review. The Family Journal, 15(2), 107-115. doi: $10.1177 / 1066480706297783$

Crippen, C., \& Brew, L. (2013). Strategies of Cultural Adaption in Intercultural Parenting. The Family Journal: Counseling and Therapy for Couples and Families, 21(3), 263-271. doi:10.1177/1066480713476664

Dalmage, H. M. (2000). Tripping on the color line: Black-white multiracial families in a racially divided world. New Brunswick, NJ: Rutgers University Press.

Davis, S. N., \& Greenstein, T. N. (2009). Gender ideology: Components, predictors, and consequences. Annual Review of Sociology, 35(1), 87-105. doi:10.1146/annurevsoc-070308-115920

DeCicco, T. L., \& Stroink, M. L. (2007). A third model of self-construal: The metapersonal self. International Journal of Transpersonal Studies, 26(1), 82-104. doi:10.24972/ijts.2007.26.1.82

Doss, B. D., Rhoades, G. K., Stanley, S. M., \& Markman, H. J. (2009). The effect of the transition to parenthood on relationship quality: An 8-year prospective 
study. Journal of Personality and Social Psychology, 96(3), 601-619. doi:10.1037/a0013969

Edwards, R., Caballero, C., \& Puthussery, S. (2009). Parenting children from 'mixed'racial, ethnic and faith backgrounds: Typifications of difference and belonging. Ethnic and Racial Studies, 33(6), 949-967.

doi:10.1080/01419870903318185

Falicov, C. J. (1995). Cross-cultural marriages. In Clinical Handbook of Couple Therapy. New York, NY: Guilford Press.

Forry, N. D., Leslie, L. A., \& Letiecq, B. L. (2007). Marital quality in interracial relationships: The role of sex role ideology and perceived fairness. Journal of Family Issues, 28(12), 1538-1552. doi:10.1177/0192513X07304466

Fu, X., Tora, J., \& Kendall, H. (2001). Marital happiness and inter-racial marriage: A study in a multi-ethnic community in Hawaii. Journal of Comparative Family Studies, 32(1), 47-60. Retrieved from https://www.jstor.org/stable/41603728

Glaser, J., Dixit, J., \& Green, D. P. (2002). Studying hate crime with the internet: What makes racists advocate racial violence? Journal of Social Issues, 58(1), 177-193. doi:10.1111/1540-4560.00255

Goldstein, L. M., \& Genero, N. (1995). Parenting hassles and friendship support as predictors of depressive symptoms in mothers of young children. Paper presented at the Biennial Meeting of the Society for Research in Child Development, Indianapolis, IN. 
Goodboy, A. K., \& Kline, R. B. (2017). Statistical and practical concerns with published communication research featuring structural equation modeling. Communication Research Reports, 34(1), 68-77. doi: 10.1080/08824096.2016.1214121

Graignic-Philippe, R., Dayan, J., Chokron, S., Jacquet, A. Y., \& Tordjman, S. (2014). Effects of prenatal stress on fetal and child development: A critical literature review. Neuroscience and Biobehavioral Reviews, 43, 137-162. doi:10.1016/j.neubiorev.2014.03.022

Gremigni, P., Mariani, L., Marracino, V., Tranquilli, A. L., \& Turi, A. (2011). Partner support and postpartum depressive symptoms. Journal of Psychosomatic Obstetrics and Gynecology, 32(3), 135-140. doi:10.3109/0167482X.2011.589017

Gudykunst, W. B., Ting-Toomey, S., \& Chua, E. (1988). Culture and Interpersonal Communication. Thousand Oaks, CA: Sage Publications, Inc.

Guzley, R. M., Araki, F., \& Chalmers, L. E. (1998). Cross-cultural perspectives of commitment: Individualism and collectivism as a framework for conceptualization. Southern Communication Journal, 64(1), 1-19. doi:10.1080/10417949809373114

Halgunseth, L. C., Ispa, J. M., \& Rudy, D. (2006). Parental control in Latino families: An integrated review of the literature. Child Development, 77(5), 1282-1297. doi:10.1111/j.1467-8624.2006.00934.x

Hammer, M. R. (2005). The intercultural conflict style inventory: A conceptual framework and measure of intercultural conflict resolution approaches. International Journal of Intercultural Relations, 29(6), 675-695. doi:10.1016/j.ijintrel.2005.08.01 
Harwood, R., Leyendecker, B., Carlson, V., Asencio, M., \& Miller, A. (2002). Handbook of Parenting Volume 4: Social Conditions and Applied Parenting, Mahwah, NJ: Taylor \& Francis Group

Haxton, C. L., \& Harknett, K. (2009). Racial and gender differences in kin support: A mixed-methods study of African American and Hispanic couples. Journal of Family Issues, 30(8), 1019-1040. doi:10.1177/0192513X09333946

Hayes, A. F. (2017). Introduction to mediation, moderation, and conditional process analysis: A regression-based approach. New York, NY: Guilford Publications.

Hofstede, G. (1980). Culture's Consequences. Beverly Hills, CA: Sage Publications.

Hofstede, G. (1983). Cultural dimensions for project management. International Journal of Project Management, 1(1), 41-48. doi:10.1016/0263-7863(83)90038-8

Hofstede, G. (1986). Cultural differences in teaching and learning. International Journal of Intercultural Relations, 10(3), 301-320. doi:10.1016/0147-1767(86)90015-5

Hogan, D. P., Eggebeen, D. J., \& Clogg, C. C. (1993). The structure of intergenerational exchanges in American families. American Journal of Sociology, 98(6), 14281458. doi:10.1086/230194

House, J. S., Landis, K. R., \& Umberson, D. (1988). Social relationships and health. Science, 241(4865), 540-545. doi:10.1126/science.3399889

House, J.S. (1981). Work stress and social support. Reading, MA: Addison-Wealey.

Howell, E. A., Mora, P., \& Leventhal, H. (2006). Correlates of early postpartum depressive symptoms. Maternal and Child Health Journal, 10(2), 149-157. doi:10.1007/s10995-005-0048-9 
Huston, T., \& Holmes, E. K. (2004). Becoming parents. In A. Vangelisti (Ed.), Handbook of Family Communication. Hillsdale, NJ: Erlbaum.

Jackson, J. B., Miller, R. B., Oka, M., \& Henry, R. G. (2014). Gender differences in marital satisfaction: A meta-analysis. Journal of Marriage and Family, 76(1), 105-129. doi:10.1111/jomf.12077

Johnson, L., Radesky, J., \& Zuckerman, B. (2013). Cross-cultural parenting: Reflections on autonomy and interdependence. Pediatrics, 131(4), 631-633. doi:10.1542/peds.2012-3451

Kamenou, N. (2008). Reconsidering work-life balance debates: Challenging limited understandings of the 'life' component in the context of ethnic minority women's experiences. British Journal of Management, 19(1), S99-S109. doi:10.1111/j.1467-8551.2008.00575.x

Kaplan, D. H., \& Woodhouse, K. (2004). Research in ethnic segregation I: Causal factors. Urban geography, 25(6), 579-585. doi:10.2747/0272-3638.25.6.579

Kawano, A. (2015). Marital struggles experienced by interracial couples: Marital struggles experienced by interracial couples: A content analysis of Japanese and American blogs. (Unpublished undergraduate thesis). Saint Mary’s College, Notre Dame, IN. Retrieved from https://www.saintmarys.edu/files/Aiko Paper.pdf

Kearns, J. N., \& Leonard, K. E. (2004). Social networks, structural interdependence, and marital quality over the transition to marriage: A prospective analysis. Journal of Family Psychology, 18(2), 383-395. doi:10.1037/0893-3200.18.2.383 
Keizer, R., Dykstra, P. A., \& Poortman, A. (2010). The transition to parenthood and wellbeing: The impact of partner status and work hour transitions. Journal of Family Psychology, 24(4), 429-438. doi:10.1037/a0020414

Kellner, J. (2009). Gender perspective in cross-cultural couples. Clinical Social Work Journal, 37(3), 224-229. doi:10.1007/s10615-009-0214-4

Kendall, F. (2012). Understanding White privilege: Creating pathways to authentic relationships across race. London, UK: Routledge.

Kenny, D. A., Kashy, D. A., \& Cook, W. L. (2006). Dyadic data analysis. New York, NY: Guilford Press.

Kim, H. K., \& McKenry, P. C. (1998). Social networks and support: A comparison of African Americans, Asian Americans, Caucasians, and Hispanics. Journal of Comparative Family Studies, 313-334. Retrieved from http://www.jstor.org/stable/41603567

Kim, R. H. (2013). Differential Impact of Racial Microaggressions on Asian Americans: Relationship to Perpetrator and Power Status (Unpublished doctoral dissertation). Teachers College, Columbia University, New York City, NY.

Kirkman, B. L., Lowe, K. B., \& Gibson, C. B. (2006). A quarter century of culture's consequences: A review of empirical research incorporating Hofstede's cultural values framework. Journal of International Business Studies, 37(3), 285-320. doi:10.1057/palgrave.jibs.8400202

Kluwer, E. S., Heesink, J. A., \& Vliert, E. V. D. (2000). The division of labor in close relationships: An asymmetrical conflict issue. Personal Relationships, 7(3), 263282. doi:10.1111/j.1475-6811.2000.tb00016.x 
Kolak, A. M., \& Volling, B. L. (2013). Coparenting moderates the association between firstborn children's temperament and problem behavior across the transition to siblinghood. Journal of Family Psychology, 27(3), 355-364. doi:10.1037/a0032864

Kraus, M. W., Piff, P. K., \& Keltner, D. (2011). Social class as culture: The convergence of resources and rank in the social realm. Current Directions in Psychological Science, 20(4), 246-250. doi:10.1177/0963721411414654

Kroeger, R. A., \& Williams, K. (2011). Consequences of Black exceptionalism? Interracial unions with Blacks, depressive symptoms, and relationship satisfaction. The Sociological Quarterly, 52(3), 400-420. doi:10.1111/j.15338525.2011.01212.x

Lachance-Grzela, M., \& Bouchard, G. (2010). Why do women do the lion's share of housework? A decade of research. Sex Roles, 63(11-12), 767-780. doi:10.1007/s11199-010-9797-z

Le, Y., McDaniel, B. T., Leavitt, C. E., \& Feinberg, M. E. (2016). Longitudinal associations between relationship quality and coparenting across the transition to parenthood: A dyadic perspective. Journal of Family Psychology, 30(8), 918-926. doi:10.1037/fam0000217

Legal Information Institute. Cornell University Law School. Loving v. Virginia. Retrieved from https://www.law.cornell.edu/supremecourt/text/388/1

Leslie, L. A., \& Letiecq, B. L. (2004). Marital quality of African American and white partners in interracial couples. Personal Relationships, 11(4), 559-574. doi:10.1111/j.1475-6811.2004.00098.x 
Lindquist, J. D., \& Kaufman-Scarborough, C. (2007). The polychronic-monochronic tendency model: PMTS scale development and validation. Time \& Society, 16(23), 253-285. doi:10.1177/0961463X07080270

Majdandžić, M., de Vente, W., Feinberg, M. E., Aktar, E., \& Bögels, S. M. (2012). Bidirectional associations between coparenting relations and family member anxiety: A review and conceptual model. Clinical Child and Family Psychology Review, 15(1), 28-42. doi:10.1007/s10567-011-0103-6

Margolin, G., Gordis, E. B., \& John, R. S. (2001). Coparenting: a link between marital conflict and parenting in two-parent families. Journal of Family Psychology, 15(1), 3-21. doi:10.1037/0893-3200.15.1.3

Markus, H. R., \& Kitayama, S. (2010). Cultures and selves: A cycle of mutual constitution. Perspectives on Psychological Science, 5(4), 420-430. doi: $10.1177 / 1745691610375557$

McLoyd, V. C., Cauce, A. M., Takeuchi, D., \& Wilson, L. (2000). Marital processes and parental socialization in families of color: A decade review of research. Journal of Marriage and Family, 62(4), 1070-1093. doi:10.1111/j.1741-3737.2000.01070.x

McSweeney, B. (2002). Hofstede's model of national cultural differences and their consequences: A triumph of faith-a failure of analysis. Human Relations, 55(1), 89-118. doi:10.1177/0018726702551004

Medina, A. M., Lederhos, C. L., \& Lillis, T. A. (2009). Sleep disruption and decline in marital satisfaction across the transition to parenthood. Families, Systems, \& Health, 27(2), 153-160. doi:10.1037/a0015762 
Mickelson, K. D., Claffey, S. T., \& Williams, S. L. (2006). The moderating role of gender and gender role attitudes on the link between spousal support and marital quality. Sex Roles, 55(1-2), 73-82. doi:10.1007/s11199-006-9061-8

Minkov, M., \& Hofstede, G. (2012a). Hofstede's fifth dimension: New evidence from the World Values Survey. Journal of Cross-Cultural Psychology, 43(1), 3-14. doi:10.1177/0022022110388567

Minkov, M., \& Hofstede, G. (2012b). Is national culture a meaningful concept? Cultural values delineate homogeneous national clusters of in-country regions. CrossCultural Research, 46(2), 133-159. doi:10.1177/1069397111427262

Muthén, B., \& Asparouhov, T. (2012). Bayesian structural equation modeling: A more flexible representation of substantive theory. Psychological Methods, 17, 313335. doi:10.1037/a0026802

Muthén, L.K. and Muthén, B.O. (1998-2017). Mplus User's Guide (8 $8^{\text {th }}$ ed.). Los Angeles, CA: Muthén \& Muthén.

Ngai, F. W., \& Ngu, S. F. (2014). Predictors of family and marital functioning at early postpartum. Journal of Advanced Nursing, 70(11), 2588-2597. doi:10.1016/j.jpsychores.2014.12.003

Östberg, V., \& Lennartsson, C. (2007). Getting by with a little help: The importance of various types of social support for health problems. Scandinavian Journal of Public Health, 35(2), 197-204. doi:10.1080/14034940600813032

Parks, P. L., Lenz, E. R., \& Jenkins, L. S. (1992). The role of social support and stressors for mothers and infants. Child: Care, Health and Development, 18(3), 151-171. doi:10.1111/j.1365-2214.1992.tb00349.x 
Perry-Jenkins, M., \& Schoppe-Sullivan, S. (2019). The transition to parenthood in social context. In B. H. Fiese, M. Celano, K. Deater-Deckard, E. N. Jouriles, \& M. A. Whisman (Eds.), APA handbooks in psychology series. APA handbook of contemporary family psychology: Foundations, methods, and contemporary issues across the lifespan (pp. 463-482). Washington, DC, US: American Psychological Association

Pinderhughes, E. E., Dodge, K. A., Bates, J. E., Pettit, G. S., \& Zelli, A. (2000). Discipline responses: Influences of parents' socioeconomic status, ethnicity, beliefs about parenting, stress, and cognitive-emotional processes. Journal of Family Psychology, 14(3), 380-400. doi:10.1037/0893-3200.14.3.380

Pinquart, M., \& Teubert, D. (2010). A meta-analytic study of couple interventions during the transition to parenthood. Family Relations, 59(3), 221-231. doi:10.1111/j.1741-3729.2010.00597.x

Preacher, K. J., Zyphur, M. J., \& Zhang, Z. (2010). A general multilevel SEM framework for assessing multilevel mediation. Psychological Methods, 15(3), 209-233. doi:10.1037/a0020141

Procidano, M. E., \& Heller, K. (1983). Measures of perceived social support from friends and from family: Three validation studies. American Journal of Community Psychology, 11(1), 1-24. doi:10.1007/BF00898416

Reichman, N. E., Teitler, J. O., Garfinkel, I., \& McLanahan, S. S. (2001). Fragile families: Sample and design. Children and Youth Services Review, 23(4-5), 303326. doi:10.1016/S0190-7409(01)00141-4 
Richardson, R. A., Barbour, N. E., \& Bubenzer, D. L. (1995). Peer relationships as a source of support for adolescent mothers. Journal of Adolescent Research, 10(2), 278-290. doi:10.1177/0743554895102005

Rockquemore, K. A., \& Brunsma, D. L. (2002). Socially embedded identities: Theories, typologies, and processes of racial identity among Black/White biracials. Sociological Quarterly, 43(3), 335-356. doi:10.1111/j.15338525.2002.tb00052.x

Rosenblatt, P. C., Karis, T. A., \& Powell, R. D. (1995). Multiracial couples: Black \& white voices. Thousand Oaks, CA: Sage Publications, Inc.

Roy, R. N., \& Rollins, A. (2019) Biracial Families: Crossing Boundaries, Blending Cultures, and Challenging Racial Ideologies, New York City, NY: Springer.

Roy, R. N., Mitchell, Y., James, A., Miller, B., \& Hutchinson, J. (2019). Experiences of family and social support during the transition to motherhood among mothers of biracial and monoracial infants. In Transitions into Parenthood: Examining the Complexities of Childrearing. Emerald Publishing Limited.

Sam, D. L., Vedder, P., Liebkind, K., Neto, F., \& Virta, E. (2008). Immigration, acculturation and the paradox of adaptation in Europe. European Journal of Developmental Psychology, 5(2), 138-158. doi:10.1080/17405620701563348

Schmitt, M. T., \& Branscombe, N. R. (2002). The meaning and consequences of perceived discrimination in disadvantaged and privileged social groups. European Review of Social Psychology, 12(1), 167-199. doi:10.1002/0470013478.ch6 
Schoppe-Sullivan, S. J., \& Mangelsdorf, S. C. (2013). Parent characteristics and early coparenting behavior at the transition to parenthood. Social Development, 22(2), 363-383. doi: 10.1111/sode.12014

Sengstock, M. C. (2001). Multicultural Families — What Makes Them Work? Sociological Practice, 3(1), 1-17. Retrieved from https://www.jstor.org/stable/43735781

Seto, A., \& Cavallaro, M. (2007). Cross-national couples in the mainland United States. The Family Journal, 15(3), 258-264. doi:10.1177/1066480707301315

Sharaievska, I., Kim, J., \& Stodolska, M. (2013). Leisure and marital satisfaction in intercultural marriages. Journal of Leisure Research, 45(4), 445-465. doi:10.18666/jlr-2013-v45-i4-3894

Shih, M., Bonam, C., Sanchez, D., \& Peck, C. (2007). The social construction of race: Biracial identity and vulnerability to stereotypes. Cultural Diversity and Ethnic Minority Psychology, 13(2), 125-133. doi:10.1037/1099-9809.13.2.125

Smedley, A., \& Smedley, B. D. (2005). Race as biology is fiction, racism as a social problem is real: Anthropological and historical perspectives on the social construction of race. American Psychologist, 60(1), 16-26. doi:10.1037/0003066X.60.1.16

Sousa, L., \& Rodrigues, S. (2009). Linking formal and informal support in multiproblem low-income families: The role of the family manager. Journal of Community Psychology, 37(5), 649-662. doi:10.1002/jcop.20313

Stuberfield, A. R. (2017). The relation between societal attitudes and the success of interracial relationships (Unpublished master thesis). Lamar University, 
Beaumont, TX. Retrieved from https://illiad-library-umassedu.silk.library.umass.edu/illiad/AMH/illiad.dll?Action=10\&Form=75\&Value=1 516221

Taras, V., Rowney, J., \& Steel, P. (2009). Half a century of measuring culture: Review of approaches, challenges, and limitations based on the analysis of 121 instruments for quantifying culture. Journal of International Management, 15(4), 357-373. doi:10.1016/j.intman.2008.08.005

Taylor, R. J., Chatters, L. M., Woodward, A. T., \& Brown, E. (2013). Racial and ethnic differences in extended family, friendship, fictive kin, and congregational informal support networks. Family Relations, 62(4), 609-624. doi:10.1111/fare. 12030

Teubert, D., \& Pinquart, M. (2010). The association between coparenting and child adjustment: A meta-analysis. Parenting: Science and Practice, 10(4), 286307. doi:10.1080/15295192.2010.492040

Thomas, V., Wetchler, J. L., \& Karis, T. (2014). Assessment and Intervention with Black-White Multiracial Couples. In Clinical Issues with Interracial Couples (pp. 129-192). London, UK: Routledge.

Tillman, K. H., \& Miller, B. (2017). The role of family relationships in the psychological wellbeing of interracially dating adolescents. Social Science Research, 65, 240252. doi:10.1016/j.ssresearch.2016.11.001

Tophoven, I. (2014). Long-Lasting, Satisfied, Bicultural United States Veterans and German Spouses: A Phenomenological Study. (Unpublished doctoral dissertation). Regent University, Virginia Beach, VA. 
Tubbs, C. Y., \& Rosenblatt, P. C. (2003). Assessment and intervention with Black-White multiracial couples. Journal of Couple \& Relationship Therapy, 2(2-3), 115-129. doi:10.1300/J398v02n02_09

Usita, P. M., \& Poulsen, S. (2003). Interracial relationships in Hawaii: Issues, benefits, and therapeutic interventions. Journal of Couple \& Relationship Therapy, 2(2-3), 73-83. doi:10.1300/J398v02n02_06

Uttal, L. (1999). Using kin for child care: Embedment in the socioeconomic networks of extended families. Journal of Marriage and the Family, 845-857. doi:10.2307/354007

Van Egeren, L. A. (2003). Prebirth predictors of coparenting experiences in early infancy. Infant Mental Health Journal: Official Publication of The World Association for Infant Mental Health, 24(3), 278-295. doi:10.1002/imhj.10056

Van Egeren, L. A. (2004). The development of the coparenting relationship over the transition to parenthood. Infant Mental Health Journal: Official Publication of The World Association for Infant Mental Health, 25(5), 453-477. doi:

10.1002/imhj.20019

Wandersman, L., Wandersman, A., \& Kahn, S. (1980). Social support in the transition to parenthood. Journal of Community Psychology, 8(4), 332-342. doi:10.1002/15206629(198010)8:4<332::AID-JCOP2290080407>3.0.CO;2-H

Wellman, B., \& Wortley, S. (1990). Different strokes from different folks: Community ties and social support. American Journal of Sociology, 96(3), 558-588. doi:10.1086/229572 
Williams, D. T. (2018). Parental depression and cooperative coparenting: A longitudinal and dyadic approach. Family Relations, 67(2), 253-269. doi:10.1111/fare.12308

Wilt, J. (2011). Normal families facing unique challenges: The psychosocial functioning of multiracial couples, parents and children. The New School Psychology Bulletin, 9(1), 7-14. Retrieved from http://www.nspb.net/index.php/nspb/article/view/188/116

Xiang, Y., Hoot, J., \& Raisor, J. (2017). Parenting Stress and Social Support among Cross-national and Traditional Families. Journal of Family Diversity in Education, 2(4), 26-41. Retrieved from http://familydiversityeducation.org/index.php/fdec

Yahirun, J. J. (2019). Intermarriage and mother-child relationships. Social Science Research, 78, 203-214. doi:10.1016/j.ssresearch.2018.12.005

Yavorsky, J. E., Kamp Dush, C. M., \& Schoppe-Sullivan, S. J. (2015). The production of inequality: The gender division of labor across the transition to parenthood. Journal of Marriage and Family, 77(3), 662-679. doi:10.1111/jomf.12189

Zhang, Y., \& Van Hook, J. (2009). Marital dissolution among interracial couples. Journal of Marriage and Family, 71(1), 95-107. doi:10.1111/j.17413737.2008.00582.x 